\title{
Prevalence, Risk Factors and Remedies for Psychiatric Illnesses among Students in Higher Education: A Comprehensive Study in University of Ruhuna
}

Patikiri Arachchige Don Shehan Nilmantha Wijesekara ( $\nabla$ nilmantha@eie.ruh.ac.lk) University of Ruhuna

Research Article

Keywords:

Posted Date: February 2nd, 2022

DOI: https://doi.org/10.21203/rs.3.rs-1275437/v1

License: (9) This work is licensed under a Creative Commons Attribution 4.0 International License. Read Full License 


\title{
Prevalence, Risk Factors and Remedies for Psychiatric Illnesses among Students in Higher Education: A Comprehensive Study in University of Ruhuna
}

\author{
Patikiri Arachchige Don Shehan Nilmantha Wijesekara ${ }^{a}$ \\ Department of Electrical and Information Engineering, Faculty of Engineering, University of Ruhuna, Galle, 80000, Southern Province, Sri \\ Lanka;nilmantha@eie.ruh.ac.lk
}

\begin{abstract}
There is no comprehensive study on the mental health of Sri Lankan undergraduate in higher education as most existing studies have been done for medical students only. It is unknown how academic and environmental factors contribute for the prevalence of psychiatric illnesses. Further, there is no sufficient information on the student/university based remedies to reduce the psychological distress of students. This research is carried out to find the overall psychological distress, well-being, prevalence percentages of psychiatric illnesses, associated risk factors and student/university remedies to overcome them. All 13 psychiatric illnesses were found with a moderate correlation among diseases having a mean prevalence percentage of 25.92 and standard deviation of 12.93 despite the prevalence of well-being factors among students and only $8 \%$ are clinically diagnosed. $89 \%$ of the students were suffering from at least one psychiatric illness and $68 \%$ were found to be psychologically distressed. Sets of overall and individual demographic, academic and environmental risk factors contributing for the prevalence of a psychiatric illness in general and in particularly were identified respectively after a Binary logistic regression analysis. $61 \%$ of the students don't receive psychiatric help from the university and are using their own remedies.
\end{abstract}

\section{Introduction}

\subsection{Background}

Generalized Anxiety Disorder (GAD) is having fear/worry or distressing thoughts about everyday life that interfere with daily living. A survey done on an online doctoral program has shown that students had anxiety in computer use, internet and online learning ${ }^{6}$. The review article ${ }^{7}$ discusses different interventions taken by students and faculties to reduce anxiety levels of nursing students. A recent study on college students have proved that highest level of anxiety is caused due to academic distress ${ }^{8}$. According to a study on Chinese overseas students; they have developed high levels of anxiety in education due to the Coronavirus Disease of 2019 (COVID19) pandemic ${ }^{9}$. It has been found that active learning can either increase or decrease anxiety according to the way it is implemented ${ }^{10}$. It has also been found that the health anxiety which is the fear of getting an illness has been increased over the last decades among students 11. According to a recent study; the test anxiety of students has been worsen due to online proctoring of examinations ${ }^{12}$. It has been found that female students tend to have higher anxiety levels than male students ${ }^{24}$. Two stage testing has reduced student anxiety compared to traditional one stage tests for students taking introduction to chemistry exams ${ }^{13}$. Mindfulness meditation has proved to reduce the anxiety levels of college students ${ }^{14}$. Animal assisted therapies have been effective in treating anxiety of Nursing students ${ }^{15}$. Another effective solution to reducing student anxiety levels is by biofeedback which is using electronic sensors to know about one's own body functions and then voluntarily reduce adverse conditions ${ }^{16}$.

There is no evidence to prove whether agoraphobia is existed among students or not ${ }^{71}$. Agoraphobia is an anxiety disorder of fear of too far from being a safe person or place or avoiding of places or situations which might cause the person to panic or feel trapped.

Only a few evidence presents for the presence of panic disorder among the students also ${ }^{72}$. Panic disorder is feeling of a sudden/unreasonable fear.

Social Anxiety Disorder (SAD)/Social phobia is a fear of being watched or judged by others. It has been found in a group of health science students in Ethiopia and authors claim that it is highly prevalent among the university students ${ }^{73}$. SAD has been found more frequently in female medical students more than other students according to findings of ${ }^{74}$. SAD has been found to be associated with internet addiction and depression ${ }^{75}$. Some studies show that social phobia can negative affect for the academic performance ${ }^{76}$.

Next major mental illness is Depression which is the mental state of having low mood, reduced energy and loss of interest. A study in 2013 had showed that one third of university students have depression in 
average ${ }^{17}$. A similar study shows that medical students have a higher chance of depression than other students ${ }^{18}$. Another study shows that around $10 \%$ of medical students have depression to the level of suicidal ideation ${ }^{19}$. Further, there is evidence to prove that Ph.D. students have higher levels of depression 22. When considering the gender differences among male and female students; male students have been reported to have higher chance of getting depressed ${ }^{24}$. The causes of depression have been found to be as high academic performance, pressure to succeed and postgraduate plans ${ }^{20}$. Academic delays due to COVID19 has also been found to worsen the effects of depression ${ }^{26}$. As depression prevention programs; Psycho-education, relaxation techniques and cognitive monitoring have been effective ${ }^{21}$. Some have suggested Digital mental health intervention programs such as internet based cognitive behavioral therapy to reduce effects of depression ${ }^{23}$. Work in ${ }^{25}$ suggests that social support from family and friends can be used to reduce the effects of depression. According to a study conducted among Sri Lankan undergraduates, $10 \%$ of students have shown major depression symptoms ${ }^{27}$. Another similar survey has found that peer students support depressed Sri Lankan students and only a few seeks professional support 28 .

Bipolar Affective Disorder (BAD) is a mood disorder which a person experiences episodes of mania (high mood, high energy and high interest) and depression interchangeably from time to time. A recent study on bipolar affective disorder shows that even though its prevalence is relatively lower than anxiety/depression; it has been increasing over the last decade ${ }^{29}$. Another study confirms the preceding fact as they have found only few bipolar affective students compared to students having schizophrenic symptoms 30. Border line personality disorder which is the illness of having varying moods has been prevalent in college students and such students have been in a higher chance of suffering from bipolar disorder ${ }^{31}$. Even though some points out that there is a negative impact for academic performance due to bipolar disorder; work in ${ }^{32}$ suggests that there is not a significant relationship between GPA and bipolar disorder.

Dissociative Disorder (DD) is a psychiatric illness which a person is disconnected from his thoughts, feelings, memories or sense of identity. Dissociative disorder has been proved to be found more in student populations than general populations according to ${ }^{33}$. It has been found in non-clinical group of students in Hong-Kong ${ }^{34}$. A study on a group of Italian university students suggests that there is a correlation between dissociation disorder and addiction to internet games ${ }^{35}$. Dissociation and several other factors have led to fear of happiness among college students ${ }^{36}$.

Eating Disorder (ED) is another mental illness that can arise among students. That is having restrictive eating or compulsive eating or irregular or inflexible eating patterns. College student populations have known to be having eating disorders and require treatment as shown in ${ }^{37}$. Eating disorder has been proved to be related to obesity; and weight status has been the predictor of eating disorder symptoms among undergraduates and graduates ${ }^{38}$. A group of researchers have found that weight motivated vegetarian students have a higher chance of having eating disorders ${ }^{39}$. Nicotine vaping which is common among college students has been found to create eating disorders in them ${ }^{40}$. A Research conducted using Malaysian university students show that nearly $14 \%$ students are suffering from eating disorders ${ }^{41}$. Non-Athletic female students who are dissatisfied with their body shapes have been found to be relatively suffering more from eating disorders 42 . Further, perfectionistic female students have shown higher levels of eating disorders as proved in ${ }^{44}$. Trait compulsiveness and impulsiveness both have been proved to cause eating disorders in students ${ }^{45}$. Cultural adaptation of dialectical behavioral therapy has been effective in treating an eating disorder of a Chinese student ${ }^{43}$. Some use dissonance-based eating disorder prevention programs to reduce eating disorders among students 46

Obsessive Compulsive Disorder (OCD) is a psychiatric illness when a person has uncontrollable, reoccurring thoughts and behaviors that are repeated. A set of college students of Kerala had been found to suffer from this disorder having taboo thoughts and mental rituals as the symptoms ${ }^{47}$. A positive relationship between Orthorexia Nervosa which is an obsession with healthy eating with restrictive behaviors; and obsessive-compulsive disorder has been found among a group of Italian university students ${ }^{48}$. Study shows that fear of COVID19 has caused university students to get symptoms of OCD ${ }^{50}$. Study suggests that left behind experience as a positive predictor of OCD and suggests improving self-esteem of a person to prevent OCD in students ${ }^{51}$. Hoarding disorder which is the difficulty in getting rid of something had caused OCD in college students ${ }^{53}$. Studies have shown that cognitive behavioral therapy which is a therapy which negative thoughts such as reoccurring thoughts are challenged in order to avoid behavioral patterns such as repeated behaviors; is used to treat OCD ${ }^{52}$.

Schizophrenia is a strong mental illness which people interpret the world abnormally with hallucinations, delusion, disordered thinking and behavior and lessened emotional expressions. A hallucination is hearing, seeing, smelling, tasting something that does not really exist. Delusions are false beliefs that are not shared by others. It has been found that there is a low probability (0.03) of finding Schizophrenia and Obsessive-compulsive disorder co-occurrence in college students ${ }^{49}$. A study on Japanese university students shows that the number of students who left the schools because of Schizophrenia has been reduced over time ${ }^{54}$. Another study on college students show that transgender students have a tendency to suffer from schizophrenia more than cisgender female students 55 . 
Paranoia is a kind of delusion that the person is threatened by others even if they aren't really threatened. Non clinical group of undergraduates with higher levels of paranoia and anxiety have been found as given in ${ }^{58}$. Research conducted in ${ }^{59}$ shows that high levels of paranoia can be found in students and investigates on how they experience it Online imagery has been effective in attenuating paranoia in college students ${ }^{56}$. Mindfulness which is being intensively aware about the thoughts and feelings of the present moment has been effective in attenuating paranoia 57.

Post-Traumatic Stress Disorder (PTSD) is a mental condition such as memory flashbacks, nightmares or severe anxiety which can occur as a result of an experience of a past traumatic event. A study done on a group of nursing students show emotional intelligence and psychological resilience as factors contributing to post-traumatic stress growth ${ }^{60} .{ }^{61}$ shows that PTSD is found in high school students and concludes that high post-traumatic growth is associated with low frequency use of substances such as Alcohol and Marijuana. According to the review conducted in ${ }^{62}$ students with PTSD tends to have a lower IQ, impaired memory, lower verbal abilities, compromised attention thus lowering the academic performance.

Psychosis is a mental state of being detached from reality which the person can experience hallucinations, delusions characterized by agitation and sleep deprivation. Screening tools such as PRIME screen revised and Structured Interview for Psychosis-risk Syndrome (SIPS) have been used in student counseling centers to screen students with psychosis ${ }^{67}$. According to research conducted using a group of British undergraduate students; financial difficulties has been a major contributor to psychosis risk 63 . Fragmented sleep, sleep hallucinations and night anxiety have been found to correlate with Psychosis like experience in college students ${ }^{64}$. A systematic review done on Psychosis related to students points out substance use, depression and younger age as risk factors for psychosis whereas self-esteem and self-concept as the protective factors 65. Another research conducted using Chinese students show that social support and resilience can act as protective factors for psychosis in students ${ }^{68}$. Students with Psychosis tend to show poorer cognitive functions than normal students 66 .

\subsubsection{Motivation}

A recent study on the overall mental well-being of medical undergraduates of Sri Lanka points out that around $40 \%$ are in severe psychological distress ${ }^{1}$. Another study in Sri Lanka done among nursing students show the evidence of presence of depression, anxiety and stress among them ${ }^{2}$. There is evidence to prove burnout in high school students due to being disturbed while studying and due to being bullied in school $^{3}$. Recent studies suggest that students' stress level has been increased during the online learning and evaluation due to the COVID19 pandemic ${ }^{5}$. Since the pandemic still exists at the time of conducting this research; it is more probable to find psychiatric illnesses among students in higher education. Preceding works fail to address how different mental illnesses exist in both clinical and non-clinical undergraduates comprehensively.

It is yet unknown which academic components cause mental illnesses such as GAD, depression in students. Most of the existing literature addresses anxiety, depression, eating disorders of students; but other potential mental illnesses such as Schizophrenia, Agoraphobia, paranoia, post-traumatic stress are least addressed in literature. In case of post-traumatic stress, it is unknown whether ragging has caused posttraumatic stress disorder in students even though a case study on university of Colombo has found ragging as a cause of stress among undergraduates ${ }^{4}$. There is no evidence to prove whether mental illnesses such as schizophrenia exists among university students in Sri Lanka or not. Most researchers have studied on medical students and it is not known how mental illnesses are spread in other disciplines.

\subsection{Problem Statement}

The research problem is the lack of comprehensive study on the mental health of Sri Lankan students in higher education which shows the distribution of such diagnosed students under different mental illnesses under diverse factors and lack of knowledge on the universities'/students' interventions to reduce the negative effects of such mental illnesses.

\subsection{Objectives}

- To identify the prevalence level of 13 mental illnesses among university students of Sri Lanka

- To identify the overall Psychological and social well-being of students in Higher education in Sri Lanka

- To investigate whether the universities/students have remedies to prevent or reduce the mental illnesses of the students and its effectiveness

- To identify the demographic factors, academic stressors, environmental stressors contributing for the prevalence of each psychiatric illness 


\subsection{Benefits to community and social value}

The research findings will play a vital aspect in determining the requirement to implement psychological distress reduction/prevention programs in universities. Since this research identifies the factors and components creating stress in students; programs can be designed by targeting the aspects which cause stress in order to reduce or prevent them. By participating in the survey; the students will engage in capacity building of their knowledge regarding their own psychological well-being. They can keep a copy of the responses to self-evaluate them. Hence both the students and institutions will be benefited from this research. By producing graduates with high emotional well-being; the society will be benefited.

\subsection{Benefits to healthcare professionals}

As this research investigates on factors causing psychological distress among students; knowing these factors will help healthcare professionals in treating students diagnosed with a particular psychiatric illness. The research may reveal hidden/not revealed factors/knowledge so far about the prevalence of psychiatric illnesses among students.

\section{Material and Methods}

\subsubsection{Ethical approval and adherence to guidelines and regulations}

Ethical approval was obtained from the Ethics review committee of University of Ruhuna and from the Vice Chancellor of university of Ruhuna in writing before the data collection. All experiments (data collection using the questionnaire) were performed in accordance with relevant guidelines/regulations (Declaration of Helsinki, SAGER guidelines). Informed consent was obtained from all the participants before the data collection. All participants' responses were collected in anonymous mode and participants' identifying information were not collected. There are no legal/social/financial issues for this research.

\subsubsection{Sample}

This research is done for the whole university since data collected from a single faculty will not provide a broad understanding about psychological state of the Sri Lankan students in higher education. Specifically, we attempt to eliminate the data set bias by a whole university study. Further, some psychiatric illnesses may be rare. By increasing the number of students for which the questionnaire is distributed; we increase the probability of finding such rare cases. The study was conducted among the undergraduates and postgraduates of university of Ruhuna.

Confidentiality and anonymity - A response by a student does not include any personal information such as student name, student identification numbers etc. We do not even collect the name of the university which the student is studying. Hence, all responses will be anonymous. The collected data will be confidentially kept (stored in google drive without sharing) with the principal investigator for a period of 2 years from the first date of data collection and then destroyed. Participants cannot be provided with any incentive/reward due to anonymity.

Participants - The students participate to the survey in their own willingness. They have the right to not to respond to the questionnaire. However, if they submit a response; that response cannot be withdrawn. That is because by providing a complete response; they have agreed and provided consent to participation for the research. At the beginning of the survey; a participant must provide consent to participate in the survey and agree that he/she has read and understood about information collected in the survey by ticking a checkbox. The information presented to the participant are purpose of the survey, participant's responsibilities, potential benefits and risks to the participant, confidentiality and anonymity of data collection, process and period of storage of data. A participant has the right to contact the principal investigator via email in case of any difficulty regarding the survey. The participants cannot be informed of the results as contact details of the participants are not collected.

Inclusion and exclusion criteria - All responses from Sri Lankan undergraduates who have finished their degree within the last 2 years or currently enrolled in a degree program included. That is because including responses from old graduates may not provide correct insight about current situation of the psychological condition of the students in higher education. We do not exclude the students who are already diagnosed with psychiatric illness by a psychiatrist since this survey is to know about students with psychiatric illnesses. Either the student is diagnosed self-reporting or by a psychiatrist; it does not matter.

The participants are contacted through head of the departments in faculties. An electronic mail is written to the head of the departments requesting to distribute the questionnaire among all students belonging to the department.

The sample consists of total responses screened with inclusion and exclusion criteria. 100 responses were received and the total number of responses after screening were also 100 since all responses satisfied 
the inclusion criteria. Therefore, the response percentage was $1.00 \%$ since university of Ruhuna has 10,000 undergraduates.

\subsubsection{Data collection tool}

The data collection tool is a comprehensive questionnaire consisting of 19 sections implemented and shared across universities in the form of a google form. Each of the section of the questionnaire is as listed below.

- Section 1 collects the demographic and academic information about the student such as gender, age, civil status, ethnicity, religion, Academic year, Overall Grade Point Average (OGPA), expected class of the degree, total family income, residence.

- Section 2 collects information about already diagnosed mental illnesses and remedies from students and the university. First a question is asked as "Have you been ever diagnosed with a psychiatric illness by a psychiatrist?". If the student responds yes; he/she will have to answer a set of more questions. First, the time of diagnosis whether it was before the commencement of the degree program or during the degree program will be asked. Next, he will be asked to tick the names of all mental illnesses that had been diagnosed previously. Then, a list of remedies is presented to the student to tick the remedies that is done by the student for the diagnosed illness. Remedies provided are medicine, mindfulness meditation, cognitive behavioral therapy, biofeedback, animal assisted therapy, relaxation techniques (Music, Sports, leisure activities), support from family and friends, cultural adaptation of dialectical behavioral therapy, drinking alcohol, smoking Nicotine or Marijuana, watching porn, dissonance-based eating disorder prevention, online social networks, online gaming. Next, the question "Select all the support received from the university to treat your psychiatric illness" Here a list is given and in addition the student can specify any other support given. The contents of the list are counseling services, cultural events organizing, providing resources for sports, music etc., financial support, multi-stage testing, None, other. Finally, we ask the student to self-evaluate the effectiveness of the students/universities remedies in treating the psychiatric illness in a scale of 1-5

- Section 3 collects information about overall distress scale of the student to assess the likelihood of having a mental disorder. For this purpose, we use the Kessler Psychological Distress Scale (KPDS) which a collection of 10 questions to measure the level of distress of a person 69 . A response has a total mark (T) ranging from 10-50 and the distress level is decided as given in Equation 1.

$$
\text { Distress level }= \begin{cases}\text { Normal } & \text { if } 10 \leq T \leq 19 \\ \text { Mild Distress } & \text { if } 20 \leq T \leq 24 \\ \text { Moderate Distress } & \text { if } 25 \leq T \leq 29 \\ \text { Severe Distress } & \text { if } 30 \leq T \leq 50\end{cases}
$$

- Section 4 collects information about the emotional well-being (Question 1-3), social well-being (Question 4-8) and psychological well-being (Question 9-14) of the student using the Mental Health Continuum Short Form (MHC-SF) 70 which consists of 14 questions. The total score (T) for a response ranges from 0 to 70 and the well-being class is classified given in Equation 2.

$$
\text { Well-being level }= \begin{cases}\text { Moderate } & \text { if } 0 \leq T \leq 14 \\ \text { Languishing } & \text { if } 15 \leq T \leq 42 \\ \text { Flourishing } & \text { if } 43 \leq T \leq 70\end{cases}
$$

- section 5 collects information about the academic components which stresses the students. The first one is "In a scale of 1-5 how much are you satisfied about the degree program?" - AS1 to know the overall satisfaction about the degree program. Next, we present academic components for the students to rate the level of stress in a scale of 1-5. We give conventional Written end semester/year end examination - AS2, online written end semester/year-end examination -AS3, oral examination (viva) - AS4, oral presentation - AS5, individual self-learning (your own studies) - AS6, participation for a physical lecture - AS7, participation for an online lecture - AS8, active learning (debates/case studies/small group discussions/role-plays etc.) involving group work - AS9, Research and project development work - AS10, online quiz - AS11, physical in-class tests - AS12, practical demonstrations AS13, industrial/professional/worksite training - AS14 as the academic components. If any academic component is not relevant to them; they can select the option "Not Applicable".

- Section 6 is on collecting information about environmental factors contributing to academic stress. We provide set of environmental factors and ask the student to mark the level of stress each factor cause 
in a scale of 1-5. If the environmental factor is not relevant to them; they can select the option "Not Applicable". The factors given are prevalence of financial difficulties-ES1, COVID19-ES2, presence of a physical illness-ES3, relationship problems-ES4, bad experience due to ragging-ES5, death/sickness of a close associate-ES6, accommodation problems-ES7, problems in the teaching-learning processES8, troubles in online learning and evaluation-ES9, lack of support for psychiatric help-ES10, having less/no time to spend for leisure/sports/music etc. -ES11. Last question is to asking the student to specify if there are any other environmental stressors.

- Section 7 collects information about GAD. First, the reader is explained with the definition of GAD. We use the Anxiety Symptom Questionnaire (ASQ) 77 with each response per question having a 2fold scale 'Yes' or 'No'. ASQ questions 9-11 are used in order to screen GAD as given in Equation 3.

$$
G A D \text { class }= \begin{cases}\text { GAD possibile } & \text { if only question } 9 \text { and } 10 \text { marked } \\ \text { Mild GAD } & \text { if all questions marked with } 1-2 \text { symptoms for question } 11 \\ \text { high GAD } & \text { if all questions marked with more than } 2 \text { symptoms for question } 11 \\ \text { Normal } & \text { if otherwise }\end{cases}
$$

- Section 8 collects information about Agoraphobia. First, the reader is explained with the definition of Agoraphobia. We use ASQ questions 5-6 in order to screen Agoraphobia as given in Equation 4.

agoraphobia class $= \begin{cases}\text { Possible } & \text { if only question 5marked } \\ \text { Mild agoraphobia } & \text { if all questions marked with } 1-2 \text { symptoms for question } 6 \\ \text { Moderate agoraphobia } & \text { if all questions marked with } 3-4 \text { symptoms for question } 6 \\ \text { Severe agoraphobia } & \text { if all questions marked with more than } 4 \text { symptoms for Q6. } \\ \text { Normal } & \text { otherwise }\end{cases}$

- Section 9 collects information about Panic Disorder (PD). First, the reader is explained with the definition of PD. We use ASQ questions 1-4 in order to screen PD as given in Equation 5.

$$
\text { panicdisorder class }= \begin{cases}\text { Not necessarily } & \text { if only question } 1 \text { and } 2 \text { marked } \\ \text { panic attack possible } & \text { if only question } 1,2 \text { and } 3 \text { marked } \\ \text { panic attack exist } & 4 \text { or more symptoms for } Q 4 \\ \text { Normal } & \text { if otherwise }\end{cases}
$$

- Section 10 collects information about SAD. First, the reader is explained with the definition of SAD. We use ASQ questions 7-8 in order to screen SAD as given in Equation 6.

$$
S A D \text { class }= \begin{cases}\text { Possible } & \text { if only question 7marked } \\ \text { Mild } S A D & \text { if all questions marked with } 1-2 \text { symptoms for question } 8 \\ \text { Moderate } S A D & \text { if all questions marked with } 3-4 \text { symptoms for question } 8 \\ \text { Severe } S A D & \text { if all questions marked with more than } 4 \text { symptoms for } Q 8 . \\ \text { Normal } & \text { if otherwise }\end{cases}
$$

- section 11 collects information about Depression. First, the reader is explained with the definition of Depression. Beck's Depression Inventory (BDI-21) 78 which is a questionnaire consisting of 21 questions with each response per question having a 4-fold scale is used to screen Depression. A response can have a score $(\mathrm{T})$ ranging from 0 to 63 and the scores are classified into depression classes as given in Equation 7.

$$
\text { depression class }= \begin{cases}\text { Normal } & \text { if } T \leq 10 \\ \text { Mild mood disturbance } & \text { if } 11 \leq T \leq 16 \\ \text { borderline clinical depression } & \text { if } 17 \leq T \leq 20 \\ \text { moderate depression } & \text { if } 21 \leq T \leq 30 \\ \text { severe depression } & \text { if } 31 \leq T \leq 40 \\ \text { extreme depression } & \text { if } 40 \leq T\end{cases}
$$


- Section 12 collects information about BAD. First, the reader is explained with the definition of BAD. Mood Disorder Questionnaire (MDQ) 79 consisting of 17 questions with each response per question having a 2-fold 'Yes' or 'No' is used to screen the students suffering from BAD as given in Equation 8.

$B A D$ class $= \begin{cases}B A D \text { present } & \text { if more than } 6 \text { yes for } Q 1-13, \text { yes for } Q 14 \& \text { moderate/serious for } Q 15 \\ \text { Normal } & \text { otherwise }\end{cases}$

- Section 13 collects information about DD. First, the reader is explained with the definition of DD. Somatoform Dissociation Questionnaire (SDQ) consists of 20 questions with each response per question having a 5-fold scale. We obtain the 5-question version which is the questions 4, 8, 13, 15 and 18 of the original SDQ-20 as SDQ-5 80 to screen the students suffering from DD. The total score for a response for SDQ ranges from 0-25. Screening criteria is given in Equation 9.

$$
D D \text { class }= \begin{cases}D D \text { present } & \text { if } 8 \leq T \\ \text { Normal } & \text { otherwise }\end{cases}
$$

- Section 14 collects information about ED. First, the reader is explained with the definition of ED. Eating Disorder Examination Questionnaire Short (EDE-QS) 81 consisting of 12 questions with each response per question having a 4-fold scale is used to screen the students suffering from ED. The total score $(\mathrm{T})$ ranges from 0-36 and the screening criteria is given in Equation 10.

$$
\text { ED class }= \begin{cases}\text { Normal } & \text { if } T \leq 7 \\ \text { Mild } E D & \text { if } \leq T \leq 14 \\ \text { moderate ED } & \text { if } 15 \leq T \leq 21 \\ \text { severe } E D & \text { if } 22 \leq T \leq 28 \\ \text { extreme } E D & \text { if } 29 \leq T\end{cases}
$$

- Section 15 collects information about OCD. First, the reader is explained with the definition of OCD. We use ASQ questions 12-13 in order to screen students with OCD using the criterion given in Equation 11.

$$
\text { OCD class }= \begin{cases}\text { OCD Present } & \text { if either or both questions marked } \\ \text { Normal } & \text { otherwise }\end{cases}
$$

- Section 16 collects information about Schizophrenia. First, the reader is explained with the definition Schizophrenia. Functional Remission of General Schizophrenia (FROGS) Scale has 19 questions with each response per question having a 5-fold scale. We use the 4-item mini-FROGS scale 82 in order to screen students with schizophrenia. A response contains a total mark (T) ranging from 0-16 and the presence of Schizophrenia is decided as given in Equation 12.

$$
\text { Schizophrenia class }= \begin{cases}\text { Schizophrenia Present } & \text { if } 8 \leq T \\ \text { Normal } & \text { otherwise }\end{cases}
$$

- Section 17 collects information about Paranoia. First, the reader is explained with the definition Paranoia. We use Paranoia Worries Questionnaire (PWQ) 83 having 5 questions with each response per question having a 5-fold scale is used in order to screen students with Paranoia. The total score (T) of a response range from 0-20 and the presence of Paranoia are decided as given in Equation 13.

$$
\text { Paranoia class }= \begin{cases}\text { Paranoia Present } & \text { if } 5 \leq T \\ \text { Normal } & \text { otherwise }\end{cases}
$$

- Section 18 collects information about PTSD. First, the reader is explained with the definition PTSD. We use ASQ questions 14-17 in order to screen students with PTSD as shown in Equation 14. We ask an additional question whether 'Was Ragging a traumatic event for you?'

$P T S D$ class $= \begin{cases}P T S D \text { present } & \text { if } Q 14 \text { marked with minimum } 1,3,2 \text { symptoms for } Q 15, Q 16, Q 17 \text { respecti. } \\ \text { Normal } & \text { Otherwise }\end{cases}$ 
- Section 19 collects information about Psychosis. First, the reader is explained with the definition Psychosis. We use Prodromal Questionnaire (PQ) 84 having 16 questions with each response per question having a 4-fold scale is used in order to screen students with Psychosis. A response conveys a total mark (T) ranging from 0 to 48 and the Psychosis classes are derived as given in Equation 15.

$$
\text { Psychosis class }= \begin{cases}\text { Normal } & \text { if } T \leq 11 \\ \text { Mild Psychosis } & \text { if } 12 \leq T \leq 23 \\ \text { moderate Psychosis } & \text { if } 24 \leq T \leq 35 \\ \text { severe Psychosis } & \text { if } 36 \leq T\end{cases}
$$

\subsubsection{Data Analysis Tool}

For the data analysis, we use Microsoft Office Excel 2016 to store and analyze data. A third-party Excel Add-on called Real Statistics is used to perform binary logistic regression for predicting the prevalence of each of the psychiatric illnesses using demographic information, academic stressors and environmental stressors. If a given stressor or demographic factor contribute positively for the presence of more than 7 psychiatric illnesses, we categorize such factors as risk factors. The risk percentage is calculated as given in Equation 16

$$
\text { Risk perce. }(R)=\frac{\text { No.of BLR coefficient positive illnesses }}{\text { Total psychiatric illnesses }}
$$

\section{Results}

\subsubsection{Population characteristics of the sample}

The mean age of the participants was 23.64 with a standard deviation of 1.40. The mean OGPA of the participants was 2.93 with a standard deviation of 0.69 . Other population characteristics are summarized in Table 1. When the collected data is analyzed statistically, the population characteristics are encoded as given in brackets of each subdivision of the characteristic. Age is received in its raw form. 


\begin{tabular}{|c|c|c|}
\hline $\begin{array}{l}\text { Population } \\
\text { characteristic }\end{array}$ & subdivision (Encoding) & percentage \\
\hline Gender & $\begin{array}{l}\text { Male (1) } \\
\text { Female (0) }\end{array}$ & $\begin{array}{l}68.3 \\
31.7\end{array}$ \\
\hline Civil status & $\begin{array}{l}\text { Unmarried (0) } \\
\text { Married (1) }\end{array}$ & $\begin{array}{l}99 \\
1\end{array}$ \\
\hline Ethnicity & $\begin{array}{l}\text { Sinhala (0) } \\
\text { Tamil (1) } \\
\text { Moor (2) } \\
\text { Other (3) }\end{array}$ & $\begin{array}{l}86.5 \\
7.7 \\
4.8 \\
1\end{array}$ \\
\hline Religion & $\begin{array}{l}\text { Buddhist (0) } \\
\text { Christian (1) } \\
\text { Muslim (2) } \\
\text { Hindu (3) }\end{array}$ & $\begin{array}{l}80.8 \\
8.7 \\
4.8 \\
5.8\end{array}$ \\
\hline Academic year & $\begin{array}{l}\text { Year } 1(0) \\
\text { Year } 2(1) \\
\text { Year } 3(2) \\
\text { Year } 4(3) \\
\text { Year } 5(4) \\
\text { completed (5) }\end{array}$ & $\begin{array}{l}15.4 \\
7.7 \\
57.7 \\
17.3 \\
0 \\
1.9\end{array}$ \\
\hline Degree class & $\begin{array}{l}\text { Normal hons. (0) } \\
\text { second lower (1) } \\
\text { second upper (2) } \\
\text { First class (3) }\end{array}$ & $\begin{array}{l}19.2 \\
15.4 \\
40.4 \\
25\end{array}$ \\
\hline $\begin{array}{l}\text { Total family in- } \\
\text { come }\end{array}$ & $\begin{array}{l}0-10000(0) \\
20000-30000(1) \\
30000-40000(2) \\
40000-50000(3) \\
50000-60000(4) \\
60000-70000(5) \\
70000-80000(6) \\
80000-90000(7) \\
90000-100000(8) \\
\text { greater than 100000 (9) }\end{array}$ & $\begin{array}{l}2.9 \\
\\
19.2 \\
10.6 \\
9.6 \\
11.5 \\
11.5 \\
5.8 \\
3.8 \\
5.8 \\
19.2\end{array}$ \\
\hline Residence & $\begin{array}{l}\text { Inside the university (0) } \\
\text { outside rented place (1) } \\
\text { from home (2) }\end{array}$ & $\begin{array}{l}78.8 \\
6.7 \\
14.4\end{array}$ \\
\hline
\end{tabular}

\subsubsection{Already diagnosed students}

Only $8 \%$ of the students are already diagnosed with a psychiatric illness by a psychiatrist. $87 \%$ of the students those who diagnosed with a psychiatric illness have been diagnosed during the degree program. They have been diagnosed with GAD, PD, SAD, Depression, ED, OCD, PSTD and psychosis. They have not been diagnosed with other psychiatric illnesses ( 5 remaining psychiatric illnesses) considered in this research.

\subsubsection{Remedies undertaken by students to reduce psychological distress}

The responses for the remedies taken by students to reduce the psychological distress are collected and the percentage of students applying the remedy is plotted as shown in Figure 1

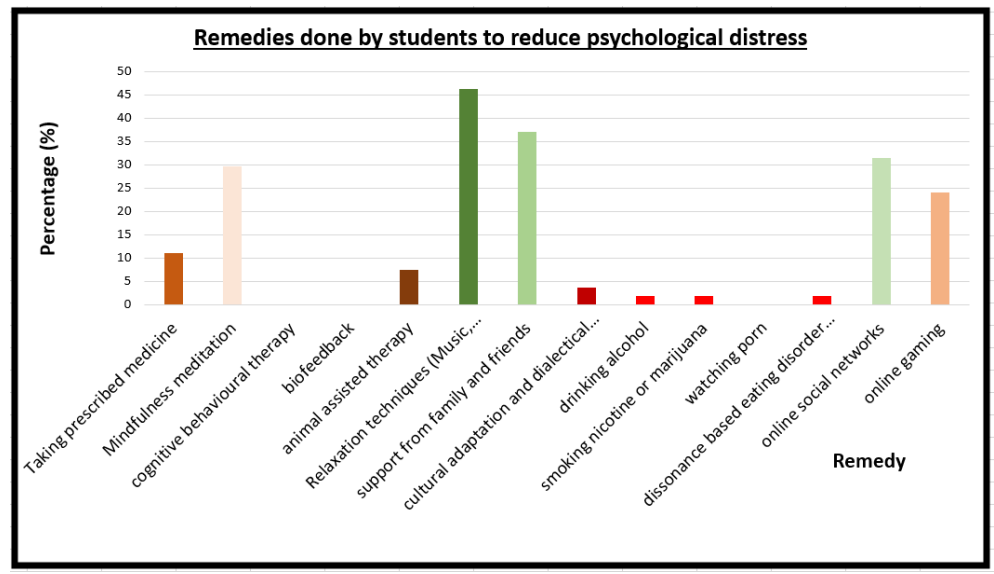

Figure 1: Distribution of percentage of students applying the remedies to reduce psychological distress 
As evident from the Figure 1, most frequently used remedy is relaxation techniques (Music, sports, leisure etc.) followed by support from family and friends, online social networks, mindfulness meditation and online gaming. A significant percentage of students take the prescribed medicine for the psychiatric illness and use animal assisted therapies. Other remedies in Figure 1 are either not used by students or insignificant.

\subsubsection{Support Received from the university to treat Psychiatric Illnesses.}

According to the responses, $61 \%$ of the students mention that they don't receive psychiatric help from the universities. The dominant support received from the universities has been providing resources for sports, music followed by cultural event organizing, counseling services and financial support according to the responses received from the students. Further, $26 \%$ of the students mention that the support received from the universities are highly effective in treating their psychiatric illnesses.

\subsubsection{Psychological Distress}

The responses for the KPDS were numerically encoded and analyzed. The total score for KPDS had a mean value of 25.07 and a standard deviation of 8.79 . The students' psychological distress were classified as shown in Figure 2.

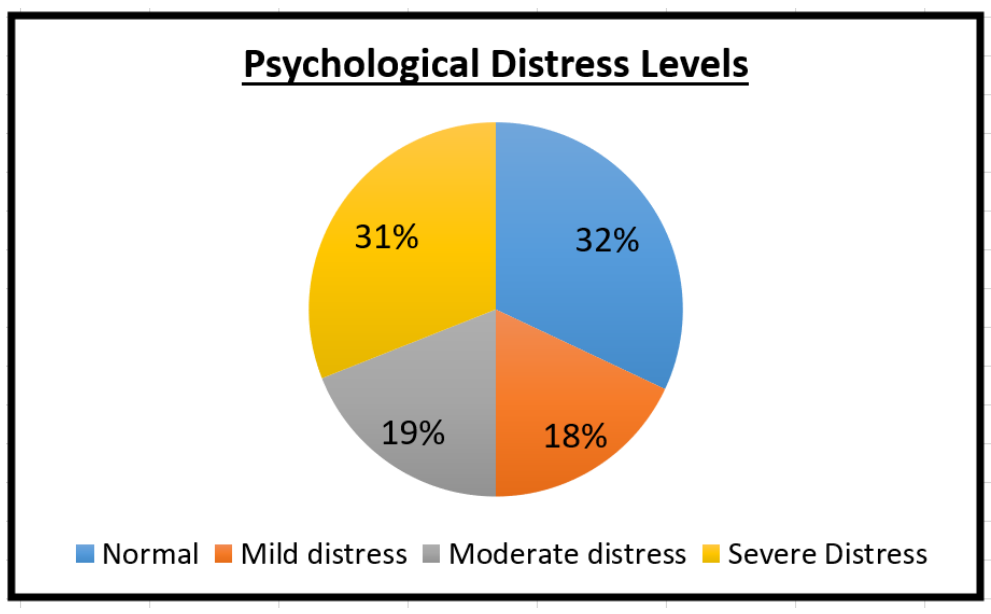

Figure 2: Psychological Distress distribution among university students

As seen from 2, only $32 \%$ of the students are Normal (not psychologically distressed). Around two thirds of the student population is psychologically distressed and $50 \%$ of the students are moderately to severely distressed. This result can be interpreted as a warning sign for the students as they show a high potential for psychiatric illnesses due to the distress.

\subsubsection{Emotional, social and Psychological Well-being}

Even though the students were proved to be psychologically distressed in the previous section; they have scored satisfactorily high scores for the MHC-SF which assesses the emotional, social and psychological well-being of the students. The total score for MHC-SF had a mean value of 33.09 and a standard deviation of 14.18. According to the responses, $10 \%$ of the students have moderate well-being, $66 \%$ have languishing well-being and $24 \%$ have flourishing well-being. This can be argued as because of the remedies/precautionary measures undertaken by the students to reduce the psychological distress. So, even though they are stressed; they have been able to maintain emotional, social and psychological well-being satisfactorily.

\subsubsection{Academic components which stresses the students}

The overall satisfaction about the academic program is as follows. $8 \%$ of the students were not satisfied at all on the degree program while $18 \%$ were slightly satisfied. $38 \%$ were moderately satisfied and $27 \%$ were highly satisfied and $9 \%$ were highly satisfied. Therefore, a slightly positively skewed bell-shaped distribution of satisfaction with the degree program can be observed as observed from 3 . 


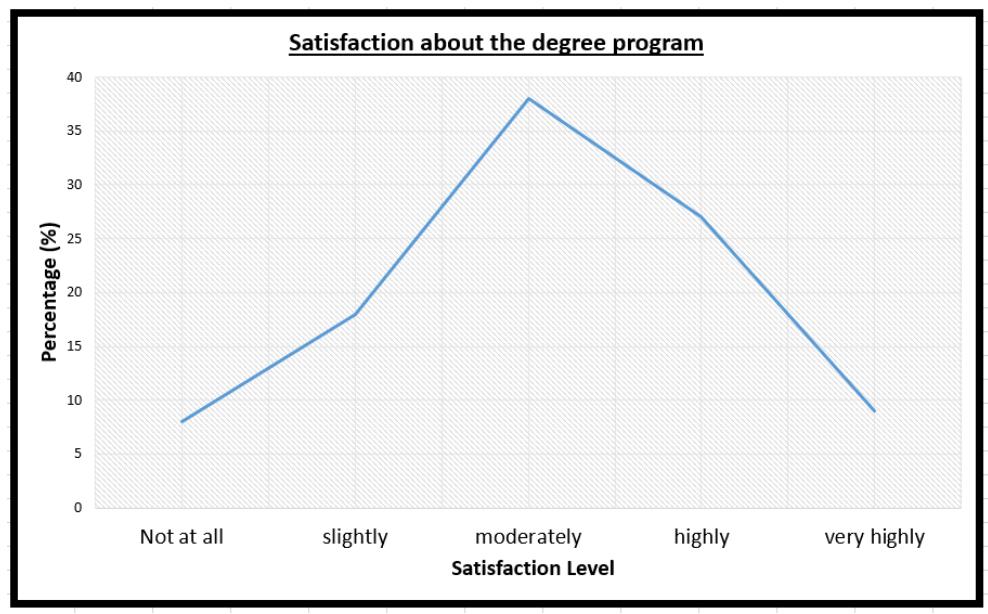

Figure 3: Satisfaction about the degree program distribution among university student

In order to understand about the academic components which stresses the students; We extract the percentage of students who responded as either highly or very highly stressed for each academic component and plot as shown in Figure 4.

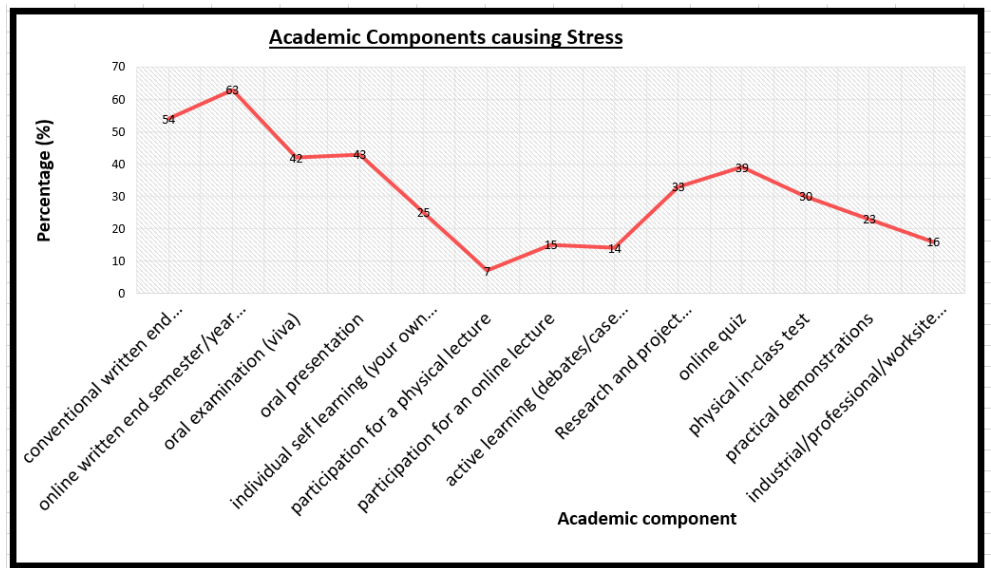

Figure 4: Percentage of each academic components causing high stress in the student.

As evident from the graph in Figure 4, the highest stress is caused by written end semester or year-end exams and the online mode being more stressful than the conventional mode. The next level of high stress can be found in oral examinations followed by online quizzes, in-class tests and research and development work. On the other hand, learning tasks such as participation for lectures and active learning cause minimum levels of stresses in the students. Worksite training and practical demonstrations seem to cause an intermediate level of stress compared to other academic components.

\subsubsection{Environmental factors contributing to academic stress}

In order to understand about the environmental stressors which stresses the students; We extract the percentage of students who responded as either highly or very highly stressed for each environmental stressor and plot as shown in Figure 5. 


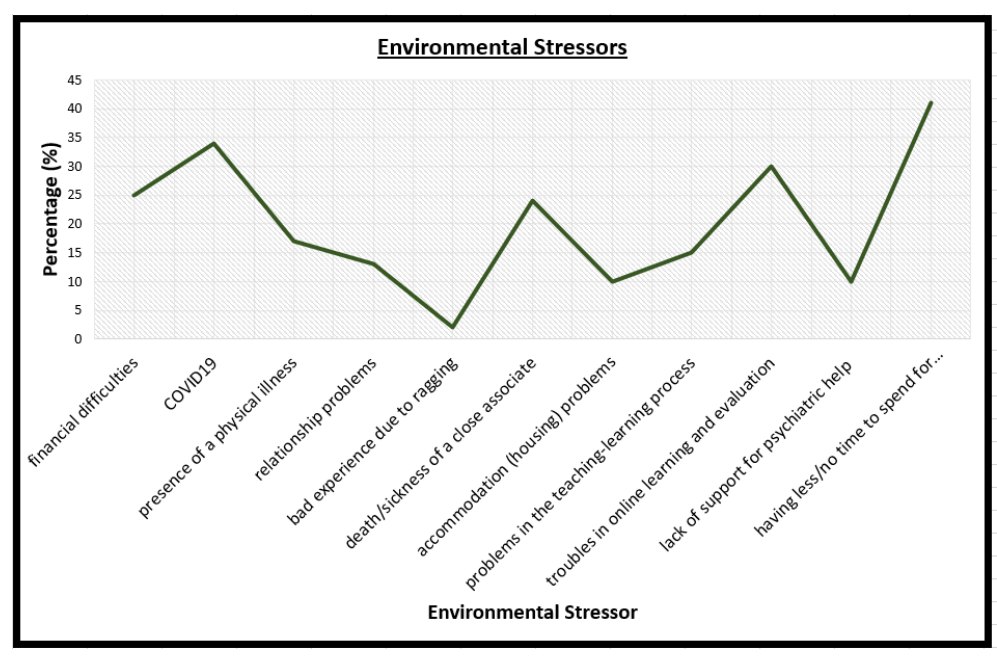

Figure 5: Percentage of each environmental stressors causing high stress in the students.

Due to the academic workload having less/no time to spend for leisure/sports/music etc. has been the dominant environmental stressor as evident from Figure 5. Next highest stressors have been COVID19 pandemic followed by troubles in online learning and evaluation which is again a consequence of COVID19. This proves that COVID19 and online learning have increased the stress levels in students. Surprisingly, financial problems, death of a close associate, presence of a physical illness etc. cause intermediate levels of stresses in students. Students report that they feel low levels of stress for relationship problems, accommodation problems and bad experience due to ragging. So, in conclusion students have felt highly stressed for stressors which are directly associated which teaching-learning process and vice versa. Further, students report that they feel stressed in following situations.

- Noisy surrounding while studying

- Language problems

- Insufficient food quality and the higher price

\subsubsection{Screening for $G A D$}

The responses for ASQ questions 9-11 were encoded with numerical values and analyzed and the results are as shown in Figure 6.

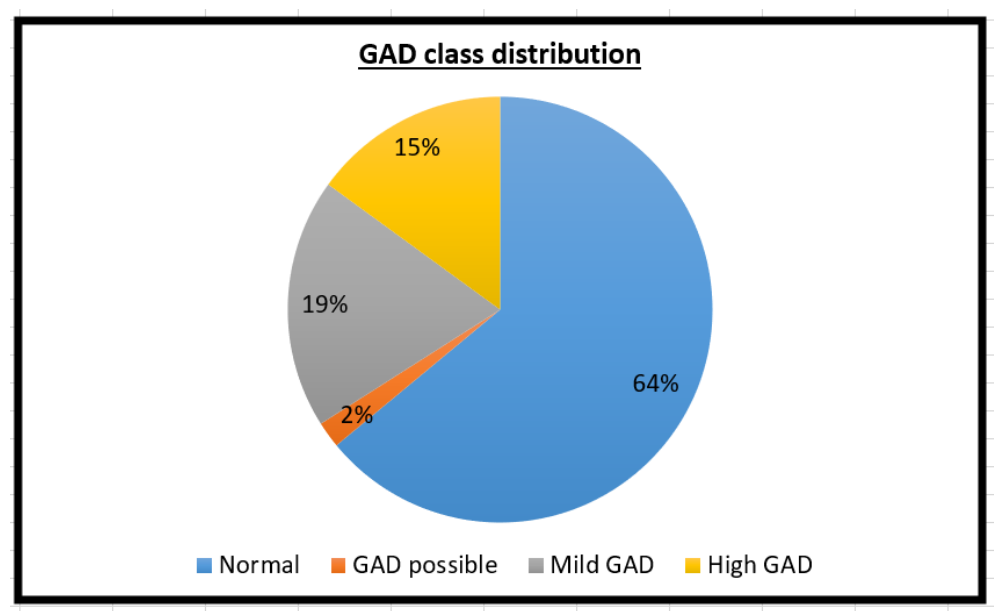

Figure 6: Classification for GAD

According to the results, nearly two thirds of the student population have been classified as Normal with respect to GAD as evident from Figure 6. Out of the remaining one third, most students show symptoms for Mild GAD and $42 \%$ show high GAD symptoms. Only a few (2\%) are categorized with the possibility to have GAD. Therefore, a significant fraction (0.15) of the population of the students has high GAD. 
The responses for ASQ questions 5-6 were encoded with numerical values and analyzed and the results are as shown in Figure 7.

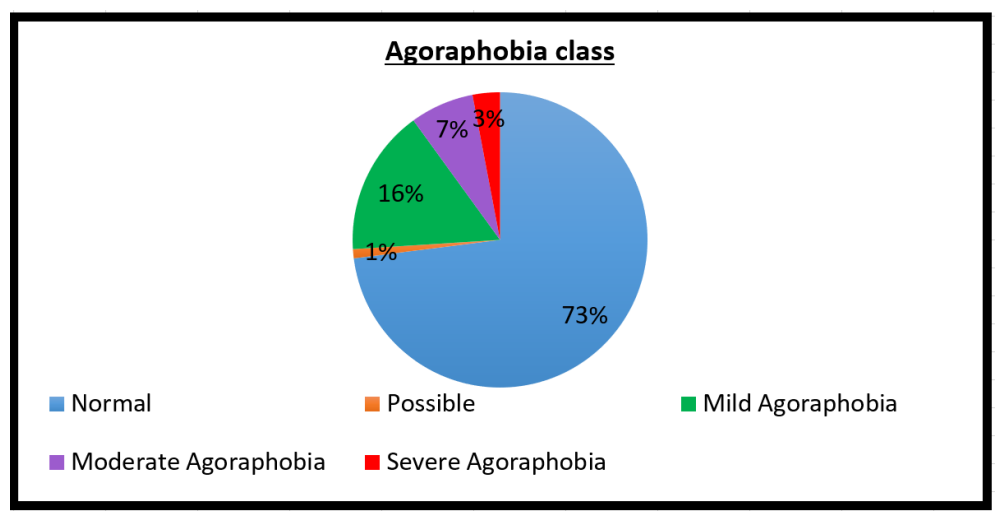

Figure 7: Classification for Agoraphobia

As evident from the Figure 7, Around one fourths of the student population show Agoraphobia symptoms. Out of the students who show Agoraphobia symptoms; most show mild symptoms while $37 \%$ (10 $\%$ of the whole population) shows Moderate to severe symptoms. Only $1 \%$ of the population showed the possibility to have Agoraphobia.

\subsubsection{Screening for PD}

The responses for ASQ 1-4 are encoded with numerical values and analyzed in order to obtain the classes of PD as shown in Figure 8.

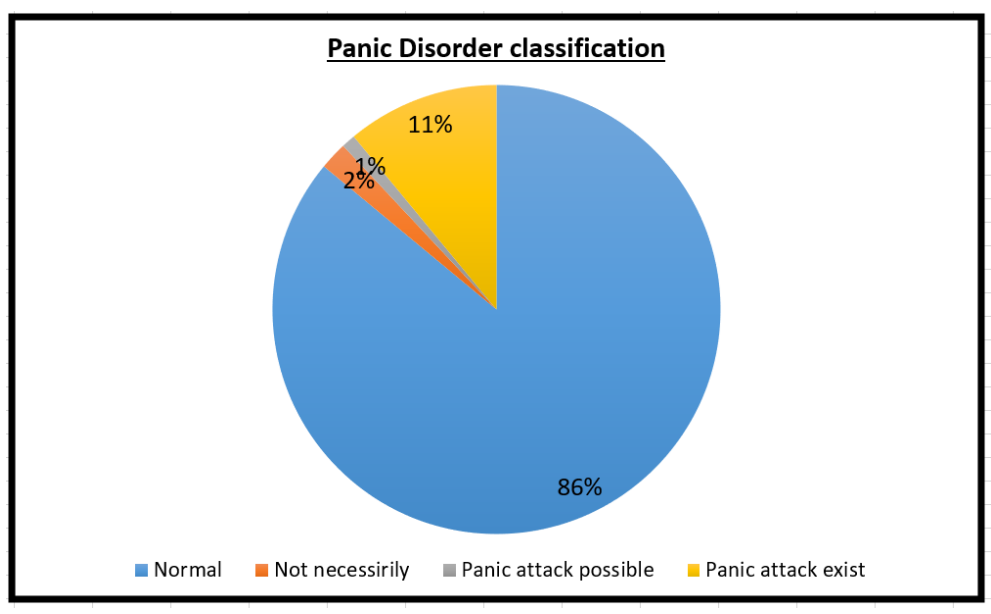

Figure 8: Classification for Panic Disorder

Panic Disorder can be found in $11 \%$ of the student population as observed in Figure 8. There are also few $(3 \%)$ students who can be possibly having a Panic attack. But majority of the student population do not have PD.

\subsubsection{Screening for $S A D$}

Students are screened for SAD using ASQ 7-8 using the responses received encoded with numerical values and classified into SAD classes after response analysis as shown in Figure 9. 


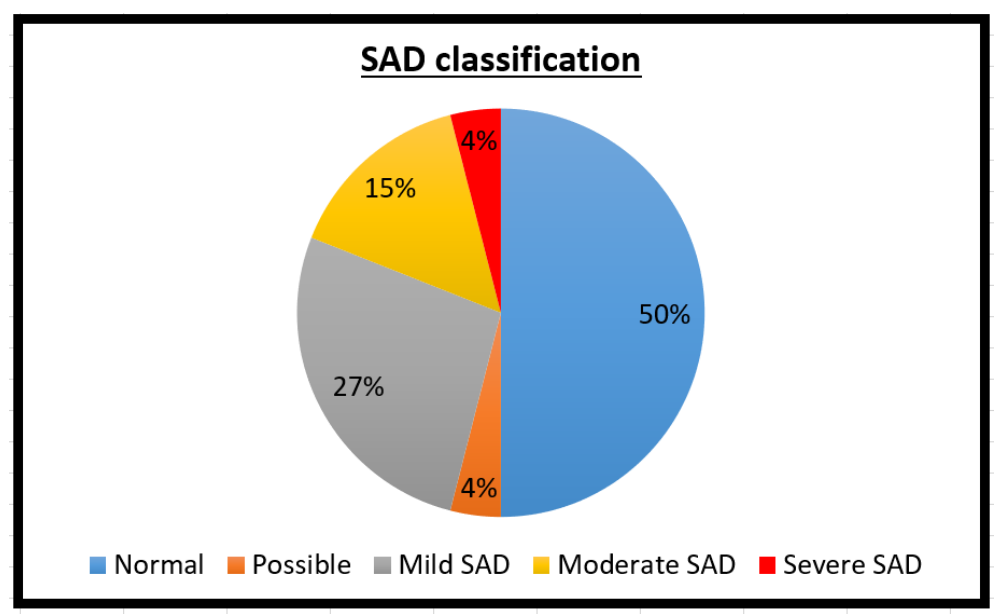

Figure 9: Classification for Social Anxiety Disorder

Half of the entire student population suffers from SAD according to the screened results in Figure 9. Out of the population suffering from SAD; only $8 \%$ show severe SAD symptoms and majority are either having mild or moderate symptoms

\subsubsection{Screening for Depression}

The responses of students for BDI-21 were encoded with numerical values and analyzed and the results are given in Figure 10. The student response "prefer not to answer" for the question regarding interest towards sex was encoded as value 1 equivalent to the response "I am less interested in sex than I used to be". Justification for doing so is to provide an intermediate response without considering it as a response between the two ends of having no change in interest towards sex and having lost interest towards sex completely.

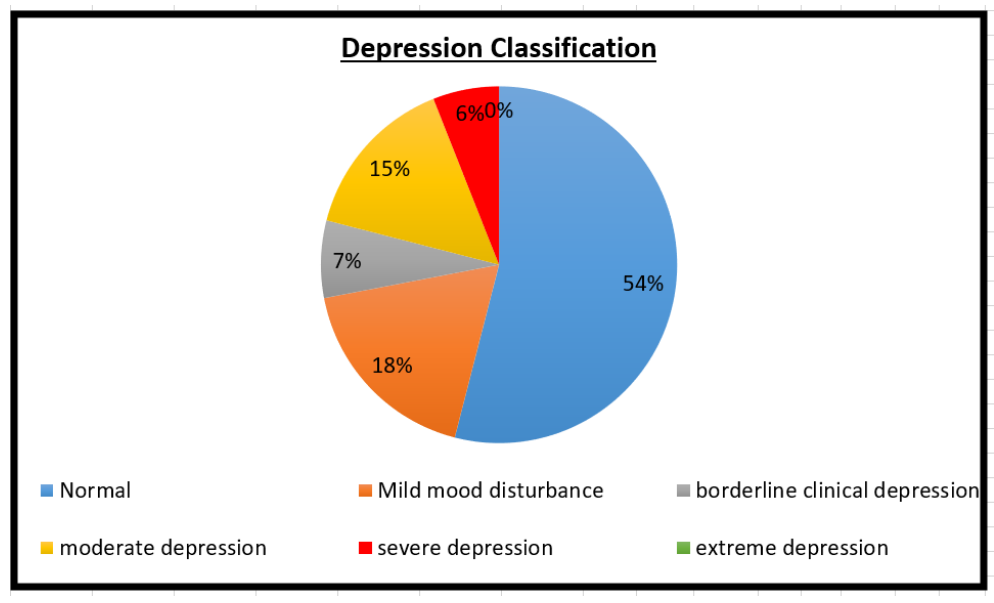

Figure 10: Classification for Depression

The mean score for the BDI-21 was 11.95 with a standard deviation of $9.85 .54 \%$ of the student population were screened as Normal while $7 \%$ were found with borderline clinical depression and $18 \%$ with mild mood disturbance. Therefore, only $21 \%$ of the responses show either moderate or severe depression while there were no cases for extreme depression. This proves that nearly one fifth of the student population have clinical depression symptoms.

\subsubsection{Screening for $B A D$}

The responses for MDQ were encoded into numerical values and analyzed to obtain the classification for BAD. The analyzed responses show that $8 \%$ of the student population has BAD while $92 \%$ does not have the disorder.

\subsubsection{Screening for $D D$}

The responses for SDQ were encoded into numerical values and analyzed. The mean score for the responses was 2.05 with a standard deviation of 3.16. According to the analysis, $11 \%$ of the student population showed symptoms for DD while $89 \%$ were Normal with respect to the DD. 


\subsubsection{Screening for ED}

The responses for EDE-QS were encoded and analyzed to obtain the classification for ED as given in Figure 11. The mean score for the EDE-QS was 6.51 with a standard deviation of 5.49.

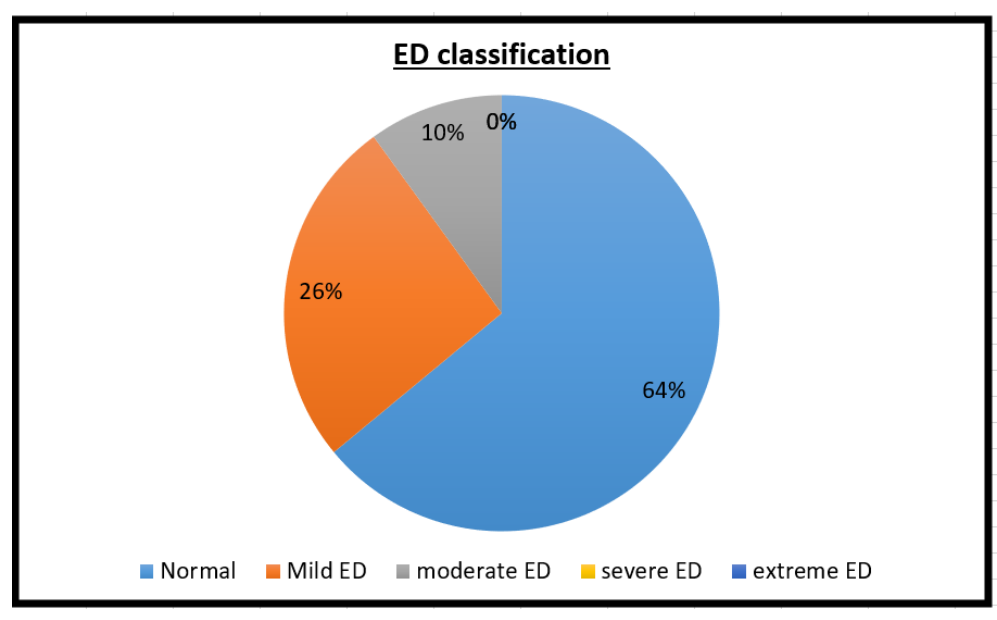

Figure 11: Classification for Eating Disorder

According to the result obtained in Figure 11, around two thirds are Normal with respect to ED and 36 $\%$ have the ED with mild to moderate severity. There were no severe or extreme cases of ED found in the responded population.

\subsubsection{Screening for $O C D$}

The responses for the ASQ 12-13 were analyzed without encoding to screen for the OCD. According to the results $34 \%$ of the students were found with the presence of OCD.

\subsubsection{Screening for Schizophrenia}

An analysis after numerical encoding of the student's responses for mini-FROGS questionnaire yields 29 $\%$ of the students showing symptoms for Schizophrenia while $71 \%$ are Normal with respect to Schizophrenia. The mean score for the min-FROGS questionnaire was 5.47 having a standard deviation of 3.48.

\subsubsection{Screening for Paranoia}

The responses for PWQ-5 were numerically encoded and analyzed. According to the analysis, $42 \%$ were screened as Paranoia present while 58 \% were screened as Normal. The mean score for the PWQ-5 questionnaire was 4.03 having a standard deviation of 4.20 .

\subsubsection{Screening for PTSD}

The responses for ASQ 14-17 were numerically encoded and analyzed. Only $3 \%$ of the students were screened as suffering from PTSD according to the analyzed results. Out of those who were screened positive; $33 \%$ (1) was reported due to ragging. But this evidence is not sufficient enough to claim whether all or most of the ragging cases directly affects PTSD or not. It only proves that there is a low possibility of causing PTSD due to ragging.

\subsubsection{Screening for Psychosis}

The student's responses for PQ were encoded numerically and analyzed to obtain the Psychosis classes as shown in 12. The mean value for the score for PQ was 9.08 with a standard deviation of 8.89 . 


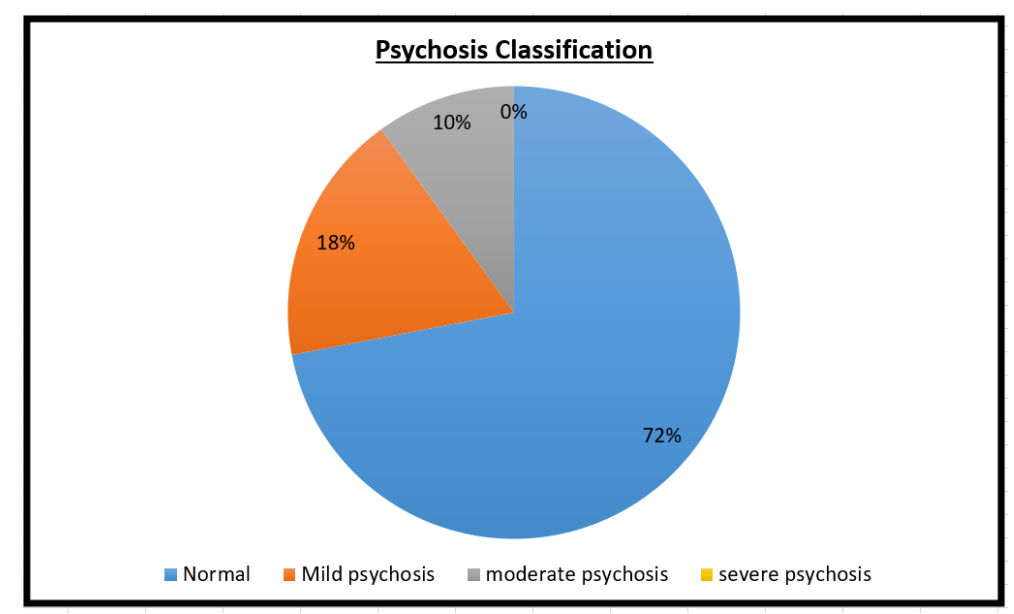

Figure 12: Classification for Psychosis

According to the results depicted in Figure 12, $28 \%$ were screened positive psychosis and out of those who were positive none showed severe psychosis. Most of positive psychosis students had mild psychosis characteristics and only $10 \%$ were screened with moderate psychosis symptoms.

\subsubsection{Overall analysis with Psychiatric illnesses}

In this section, we convert all multi-class classifications of psychiatric illnesses into binary classes. The two classes are "Normal" and "Psychiatric Illness present" where psychiatric illness is one of the 13 illnesses analyzed in this research. Here, we put the class "Possible" also as Normal and all other classes such as "Mild", "Moderate", "Severe" into "Psychiatric illness present class". After the classification, we plot the percentage of "psychiatric illness present" class as shown in the Figure 13

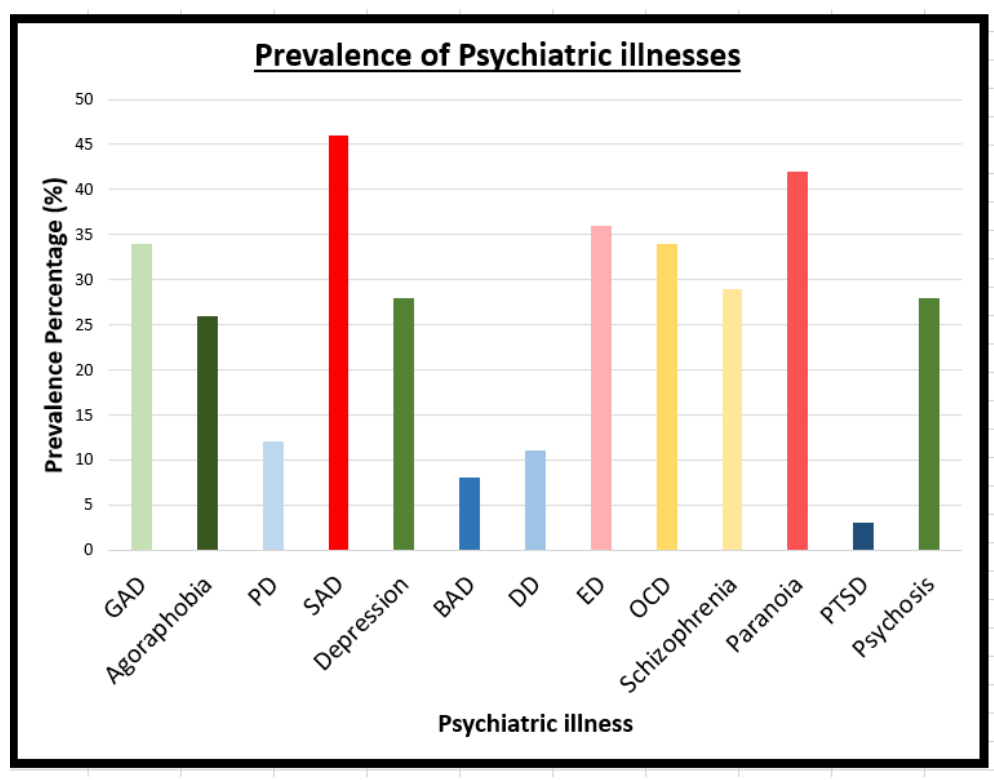

Figure 13: Prevalence rate of Psychiatric illnesses among university students.

According to the result in Figure 13, the descending order of prevalence percentage of psychiatric illnesses is SAD, Paranoia, ED, OCD, GAD, Schizophrenia, Psychosis, Depression, Agoraphobia, PD, DD, BAD and PTSD. The prevalence percentage of PTSD is low as $3 \%$ and that of SAD is high as $46 \%$. Another important thing to note here is that all psychiatric illnesses have a set of students screened positive.

Now let us analyze the distribution of psychiatric illnesses. Here, we check the students without any psychiatric illnesses against who have only 1 , only 2 , only 3 , only 4 , only 5 and greater than 5 as shown in Figure 14. 


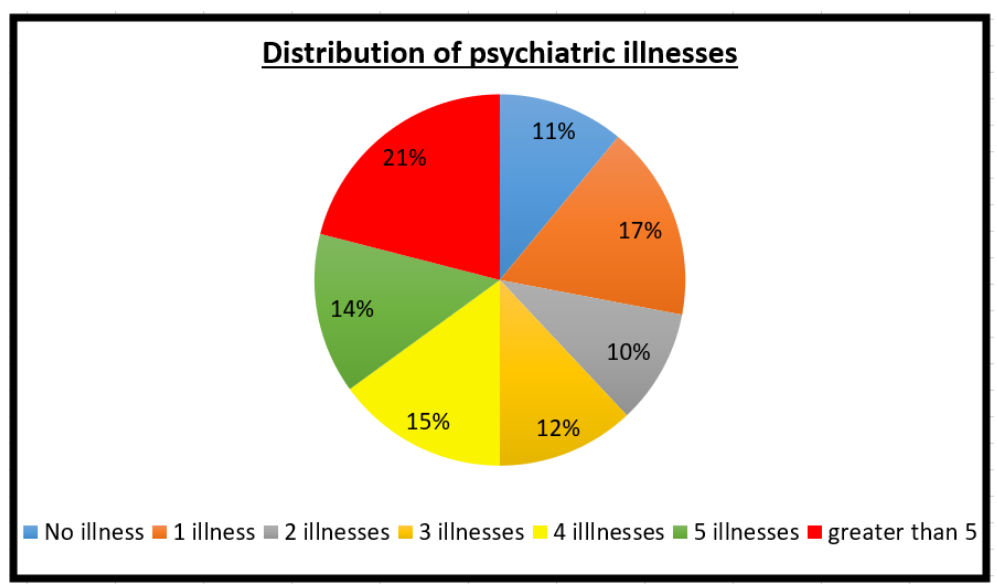

Figure 14: Psychiatric illness distribution among students

As evident from the pie chart given in Figure 14, $89 \%$ of the students have 1 or more psychiatric illnesses. Further, the students with 1 illness is only $17 \%$. So, the students with multiple psychiatric illnesses are high as $72 \%$ which can be considered as a danger sign. This result proves that majority of the students need to seek psychiatric assistance from trained professionals. On the other hand, only $8 \%$ have visited a psychiatrist and seek medical advice. Therefore, there is a huge gap among psychiatrically ill students those who have seek medical advice and those who haven't. For instance, as shown in section on already diagnosed diseases; they have not been diagnosed for Agoraphobia, BAD, DD, Schizophrenia, paranoia but as proved in this section; there are indeed students who have been screened positive for these undiagnosed diseases as well in large numbers.

\subsubsection{Statistical Analysis}

In order to understand the correlation between the illnesses, we find out the Pearson correlation coefficient for the presence or absence of illness between the psychiatric illnesses. The calculated coefficients are as shown in Table 2.

Table 2: Pearson correlation coefficient between the occurrence of psychiatric illnesses among students

\begin{tabular}{|c|c|c|c|c|c|c|c|c|c|c|c|c|c|}
\hline & GAD & Agor. & PD & SAD & Depr. & BAD & DD & ED & OCD & schi. & paran. & PTSD & Psych. \\
\hline GAD & 1.00 & 0.25 & 0.12 & 0.25 & 0.39 & 0.01 & 0.00 & 0.05 & 0.08 & 0.26 & 0.25 & 0.11 & 0.37 \\
\hline Agor. & 0.25 & 1.00 & 0.27 & 0.20 & 0.48 & -0.01 & 0.29 & 0.15 & 0.13 & 0.16 & 0.21 & 0.29 & 0.32 \\
\hline PD & 0.12 & 0.27 & 1.00 & 0.17 & 0.09 & 0.09 & 0.13 & 0.06 & 0.20 & 0.12 & 0.12 & 0.10 & -0.06 \\
\hline SAD & 0.25 & 0.20 & 0.17 & 1.00 & 0.32 & 0.00 & 0.16 & 0.08 & 0.00 & 0.07 & 0.20 & -0.06 & 0.22 \\
\hline Depr. & 0.39 & 0.48 & 0.09 & 0.32 & 1.00 & 0.25 & 0.12 & 0.14 & 0.14 & 0.07 & 0.35 & 0.19 & 0.36 \\
\hline BAD & 0.01 & -0.01 & 0.09 & 0.00 & 0.25 & 1.00 & 0.01 & 0.01 & 0.02 & -0.03 & 0.12 & 0.16 & -0.02 \\
\hline DD & 0.00 & 0.29 & 0.13 & 0.16 & 0.12 & 0.01 & 1.00 & 0.20 & 0.29 & 0.06 & 0.35 & 0.31 & 0.42 \\
\hline ED & 0.05 & 0.15 & 0.06 & 0.08 & 0.14 & 0.01 & 0.20 & 1.00 & 0.12 & 0.30 & 0.29 & -0.01 & 0.27 \\
\hline OCD & 0.08 & 0.13 & 0.20 & 0.00 & 0.14 & 0.02 & 0.29 & 0.12 & 1.00 & 0.05 & 0.33 & 0.12 & 0.16 \\
\hline schi. & 0.26 & 0.16 & 0.12 & 0.07 & 0.07 & -0.03 & 0.06 & 0.30 & 0.05 & 1.00 & 0.13 & -0.11 & 0.19 \\
\hline paran. & 0.25 & 0.21 & 0.12 & 0.20 & 0.35 & 0.12 & 0.35 & 0.29 & 0.33 & 0.13 & 1.00 & 0.09 & 0.42 \\
\hline PTSD & 0.11 & 0.29 & 0.10 & -0.06 & 0.19 & 0.16 & 0.31 & -0.01 & 0.12 & -0.11 & 0.09 & 1.00 & 0.28 \\
\hline Psych. & 0.37 & 0.32 & -0.06 & 0.22 & 0.36 & -0.02 & 0.42 & 0.27 & 0.16 & 0.19 & 0.42 & 0.28 & 1.00 \\
\hline
\end{tabular}

As evident from correlation coefficient table in 2, there was no pair of diseases which showed strong correlation between each other. However as observed from the bold coefficients in Table 2, medium correlation had existed between the following pairs of illnesses.

- GAD and depression

- GAD and psychosis

- Agoraphobia and Depression

- SAD and depression

- Depression and Paranoia

- Depression and psychosis 
- DD and Paranoia

- DD and PTSD

- DD and psychosis

- ED and schizophrenia

- OCD and paranoia

- Paranoia and psychosis

All the negative correlation coefficients are small (less than 0.3); hence even though negative correlation exists, such effects are minimum. Therefore, possibility of coexisting psychological illnesses between above pairs has been medium.

We further investigate the factors (demographic and stressors) contributing for the causing of each of the psychiatric illnesses. For that purpose, we first encode the population characteristics, academic stressors and the environmental stressors as the predictors and the presence/absence of a particular illness as the dependent variable for Binary Logistic Regression (BLR).

Factors contributing for $G A D$. Binary logistic regression coefficients and odds ratios for each of the predictors of GAD is given in Table 3. Acronyms AS stands for Academic Stressor and ES stands for Environmental Stressor in table 3 and they are listed in the methodology section.

Table 3: Binary logistic regression coefficient and odds ratio table for predicting GAD

\begin{tabular}{|l|l|l||l|l|l|}
\hline Predictor & Coefficient & $\begin{array}{l}\text { Odds } \\
\text { ratio }\end{array}$ & Predictor & Coefficient & $\begin{array}{l}\text { Odds } \\
\text { ratio }\end{array}$ \\
\hline Gender & 0.34 & 1.41 & Age & -0.49 & 0.61 \\
\hline $\begin{array}{l}\text { Civil } \\
\text { status }\end{array}$ & -20.44 & 0.00 & Ethnicity & -0.39 & 0.67 \\
\hline Religion & 0.8 & 2.22 & $\begin{array}{l}\text { Academid } \\
\text { year }\end{array}$ & 0.03 & 1.03 \\
\hline $\begin{array}{l}\text { current } \\
\text { OGPA }\end{array}$ & 0.73 & 2.08 & $\begin{array}{l}\text { degree } \\
\text { class }\end{array}$ & 0.21 & 1.24 \\
\hline Income & -0.03 & 0.97 & AS1 & -0.06 & 0.95 \\
\hline AS2 & -0.27 & 0.76 & AS3 & -0.06 & 0.94 \\
\hline AS4 & 0.30 & 1.35 & AS5 & -0.93 & 0.39 \\
\hline AS6 & 0.82 & 2.26 & AS7 & 0.26 & 1.30 \\
\hline AS8 & -2.28 & 0.10 & AS9 & 0.18 & 1.20 \\
\hline AS10 & 0.85 & 2.33 & AS11 & 0.99 & 2.68 \\
\hline AS12 & -0.13 & 0.87 & AS13 & 0.49 & 1.63 \\
\hline AS14 & -0.14 & 0.87 & ES1 & 0.29 & 1.33 \\
\hline ES2 & 0.82 & 2.28 & ES3 & 0.36 & 1.43 \\
\hline ES4 & 0.75 & 2.13 & ES5 & -0.91 & 0.40 \\
\hline ES6 & 0.16 & 1.18 & ES7 & 0.93 & 2.52 \\
\hline ES8 & -0.63 & 0.53 & ES9 & -0.49 & 0.61 \\
\hline ES10 & -0.72 & 0.49 & ES11 & 0.46 & 1.59 \\
\hline
\end{tabular}

As seen in Table 3, BLR yields a coefficient of 0.34 and odds ratio of 1.40 for the gender concluding that there is $40 \%$ higher chance for finding GAD in males than females. Probability of finding GAD seems to reduce with the increment of age as coefficient being negative (-0.49) and having odds ratio of 0.61 . However with academic year, the probability of finding GAD increases by $3 \%$. GAD is found in unmarried students resulting a large negative coefficient. As odds ratio for ethnicity is 0.67 there is less possibility of occurring GAD when the race is not Sinhalese. A positive coefficient (0.8) in religion with a odds ratio of 2.22 indicates that when the student is a non-Buddhist; the tendency for having GAD increases. OGPA and degree class also contribute positively for having GAD among students suggested by positive coefficients and large odds ratios as seen in Table 3. With the increment of family income class; the tendency to find GAD decreases as suggested by a negative coefficient of -0.03 . As shown in bold fonts in table 3, the academic stressors 6,7,9,10,11,13 and environmental stressors 1,2,3,4,6,7 and 11 have contributed positively for the prevalence of GAD in students and thus can be considered as risk factors for GAD.

Factors contributing for Agoraphobia. Binary logistic regression coefficients and odds ratios for each of the predictors of Agoraphobia is given in Table 4. 


\begin{tabular}{|l|l|l||l|l|l|}
\hline Predictor & Coefficient & $\begin{array}{l}\text { Odds } \\
\text { ratio }\end{array}$ & Predictor & Coefficient & $\begin{array}{l}\text { Odds } \\
\text { ratio }\end{array}$ \\
\hline Gender & 4.21 & 67.63 & Age & -2.08 & 0.12 \\
\hline $\begin{array}{l}\text { Civil } \\
\text { status }\end{array}$ & 36.17 & $5.13 \mathrm{E} 15$ & Ethnicity & 12.88 & $3.93 \mathrm{E} 05$ \\
\hline Religion & -14.64 & 0.00 & $\begin{array}{l}\text { Academid } \\
\text { year }\end{array}$ & 5.06 & 157.28 \\
\hline $\begin{array}{l}\text { current } \\
\text { OGPA }\end{array}$ & -1.92 & 0.15 & $\begin{array}{l}\text { degree } \\
\text { class }\end{array}$ & -2.77 & 0.06 \\
\hline Income & 2.52 & 12.44 & AS1 & -3.58 & 0.03 \\
\hline AS2 & -4.71 & 0.01 & AS3 & 1.92 & 6.82 \\
\hline AS4 & 9.11 & $9.02 \mathrm{E} 03$ & AS5 & -3.09 & 0.05 \\
\hline AS6 & 6.25 & 518.02 & AS7 & -2.7 & 0.07 \\
\hline AS8 & 0.53 & 1.70 & AS9 & 1.83 & 6.22 \\
\hline AS10 & 2.50 & 12.23 & AS11 & -1.93 & 0.14 \\
\hline AS12 & -10.5 & 0.00 & AS13 & 10.06 & $2.34 \mathrm{E} 04$ \\
\hline AS14 & 7.33 & $1.52 \mathrm{E} 03$ & ES1 & -1.00 & 0.37 \\
\hline ES2 & 7.97 & $2.91 E 03$ & ES3 & -4.58 & 0.01 \\
\hline ES4 & 2.07 & 7.95 & ES5 & 3.49 & 32.93 \\
\hline ES6 & -6.49 & 0.00 & ES7 & -0.53 & 0.59 \\
\hline ES8 & 4.8 & 121.97 & ES9 & -8.67 & 0.00 \\
\hline ES10 & 0.07 & 1.07 & ES11 & -2.46 & 0.09 \\
\hline
\end{tabular}

As seen in Table 4, BLR yields a coefficient of 4.21 and odds ratio of 67.63 for the gender concluding that there is a very higher chance for finding Agoraphobia in males than females. Probability of finding Agoraphobia seems to reduce with the increment of age as coefficient being negative $(-2.08)$ and having odds ratio of 0.12. However with academic year, the probability of finding Agoraphobia increases very significantly as proved by the odds ratio of 157.28. Agoraphobia is more likely to be found in married students resulting a large positive coefficient of 36.17. As odds ratio for ethnicity is 3.93E05, there is very high possibility of occurring Agoraphobia when the race is not Sinhalese. A negative coefficient (-14.64) in religion with a odds ratio of 0.00 indicates that when the student is a Buddhist; the tendency for having Agoraphobia is very high. Current OGPA and degree class contribute negatively for having Agoraphobia among students suggested by negative coefficients and small odds ratios as seen in Table 4 . The presence of Agoraphobia tends to increase with the increment of the income class as suggested by positive coefficient of 2.52. As shown in bold fonts in table 4, the academic stressors 3,4,8,9,10,13,14 and environmental stressors $2,4,5,8$ and 10 have contributed positively for the prevalence of Agoraphobia in students and thus can be considered as risk factors for Agoraphobia.

Factors contributing for PD. Binary logistic regression coefficients and odds ratios for each of the predictors of $\mathrm{PD}$ is given in Table 5. 


\begin{tabular}{|l|l|l||l|l|l|}
\hline Predictor & Coefficient & $\begin{array}{l}\text { Odds } \\
\text { ratio }\end{array}$ & Predictor & Coefficient & $\begin{array}{l}\text { Odds } \\
\text { ratio }\end{array}$ \\
\hline Gender & -6.5 & 0.00 & Age & -0.49 & 0.61 \\
\hline $\begin{array}{l}\text { Civil } \\
\text { status }\end{array}$ & -20.74 & 0.00 & Ethnicity & 23.78 & $2.12 \mathrm{E} 10$ \\
\hline Religion & 2.83 & 16.91 & $\begin{array}{l}\text { Academii } \\
\text { year }\end{array}$ & 0.18 & 1.20 \\
\hline $\begin{array}{l}\text { current } \\
\text { OGPA }\end{array}$ & 23.84 & $2.26 \mathrm{E} 10$ & $\begin{array}{l}\text { degree } \\
\text { class }\end{array}$ & -35.63 & 0 \\
\hline Income & 3.33 & 28.04 & AS1 & 8.93 & $7.58 \mathrm{E} 03$ \\
\hline AS2 & -25.08 & 0.00 & AS3 & 5.47 & 237.41 \\
\hline AS4 & 23.57 & $1.73 E 10$ & AS5 & -13.94 & 0.00 \\
\hline AS6 & 6.06 & 427.66 & AS7 & 9.63 & $1.52 \mathrm{E} 04$ \\
\hline AS8 & -15.81 & 0.00 & AS9 & 3.26 & 26.10 \\
\hline AS10 & 29.09 & $4.28 \mathrm{E} 12$ & AS11 & -13.38 & 0.00 \\
\hline AS12 & 25.9 & $1.77 \mathrm{E} 11$ & AS13 & 0.29 & 1.34 \\
\hline AS14 & -14.39 & 0.00 & ES1 & 3.23 & 25.33 \\
\hline ES2 & -7.04 & 0.00 & ES3 & 19.52 & $2.99 \mathrm{E} 8$ \\
\hline ES4 & 4.68 & 107.55 & ES5 & 14.25 & $1.55 \mathrm{E} 06$ \\
\hline ES6 & -20.09 & 0.00 & ES7 & 5.07 & 159.23 \\
\hline ES8 & 1.83 & 6.25 & ES9 & 14.67 & $2.36 \mathrm{E} 06$ \\
\hline ES10 & 0.95 & 2.6 & ES11 & 3.80 & 44.82 \\
\hline
\end{tabular}

As seen in Table 5, BLR yields a coefficient of -6.5 and odds ratio of 0.00 for the gender concluding that there is a very higher chance for finding PD in females than males. Probability of finding PD seems to reduce with the increment of age as coefficient being negative (-0.49) and having odds ratio of 0.61 . However with academic year, the probability of finding PD increases by $20 \%$. PD is found very highly in unmarried students resulting a large negative coefficient. As odds ratio for ethnicity is 2.12E10 there is a very high possibility of occurring PD when the race is not Sinhalese. A positive coefficient (2.83) in religion with a odds ratio of 16.91 indicates that when the student is a non- Buddhist; the tendency for having PD increases drastically. Current OGPA increment tends to increase the chance of finding students with PD as suggested by positive coefficient of 23.84. But, the Degree class contributes negatively for having PD among students suggested by negative coefficients and zero odds ratio as seen in Table 5 . The increment of the family income class increases the probability of finding a student with PD as suggested by positive coefficient of 3.33. As shown in bold fonts in table 5 , the academic stressors $1,3,4,6,7,9,10,12,13$ and environmental stressors 1,3,4,5,7,8,9,10 and 11 have contributed positively for the prevalence of PD in students and thus can be considered as risk factors for PD.

Factors contributing for $S A D$. Binary logistic regression coefficients and odds ratios for each of the predictors of SAD is given in Table 6. 


\begin{tabular}{|l|l|l||l|l|l|}
\hline Predictor & Coefficient & $\begin{array}{l}\text { Odds } \\
\text { ratio }\end{array}$ & Predictor & Coefficient & $\begin{array}{l}\text { Odds } \\
\text { ratio }\end{array}$ \\
\hline Gender & -1.43 & 0.24 & Age & -0.89 & 0.41 \\
\hline $\begin{array}{l}\text { Civil } \\
\text { status }\end{array}$ & -21.99 & 0.00 & Ethnicity & -4.25 & 0.01 \\
\hline Religion & 2.55 & 12.86 & $\begin{array}{l}\text { Academic } \\
\text { year }\end{array}$ & 1.34 & 3.84 \\
\hline $\begin{array}{l}\text { current } \\
\text { OGPA }\end{array}$ & 0.16 & 1.18 & $\begin{array}{l}\text { degree } \\
\text { class }\end{array}$ & -0.08 & 0.93 \\
\hline Income & -0.26 & 0.77 & AS1 & -0.25 & 0.78 \\
\hline AS2 & 0.41 & 1.51 & AS3 & 0.11 & 1.12 \\
\hline AS4 & 0.03 & 1.03 & AS5 & -0.54 & 0.58 \\
\hline AS6 & 0.09 & 1.10 & AS7 & 0.7 & 2.01 \\
\hline AS8 & -0.84 & 0.43 & AS9 & 0.36 & 1.43 \\
\hline AS10 & 0.30 & 1.36 & AS11 & -0.49 & 0.61 \\
\hline AS12 & 0.23 & 1.26 & AS13 & -0.14 & 0.87 \\
\hline AS14 & 0.31 & 1.36 & ES1 & 0.01 & 1.01 \\
\hline ES2 & 0.62 & 1.86 & ES3 & 0.63 & 1.88 \\
\hline ES4 & 0.19 & 1.21 & ES5 & -0.37 & 0.69 \\
\hline ES6 & 0.04 & 1.04 & ES7 & 0.03 & 1.03 \\
\hline ES8 & -0.68 & 0.51 & ES9 & 0.92 & 2.51 \\
\hline ES10 & -0.04 & 0.96 & ES11 & 0.21 & 1.24 \\
\hline
\end{tabular}

As seen in Table 6, BLR yields a coefficient of -1.43 and odds ratio of 0.24 for the gender concluding that there is $76 \%$ higher chance for finding SAD in females than males. Probability of finding SAD seems to reduce with the increment of age as coefficient being negative (-0.89) and having odds ratio of 0.41 . However with academic year, the probability of finding SAD increases by very large margin $(284 \%$ increment per academic year). SAD is found in unmarried students resulting a large negative coefficient. As odds ratio for ethnicity is 0.01 there is less possibility of occurring SAD when the race is not Sinhalese. A positive coefficient (2.55) in religion with a odds ratio of 12.86 indicates that when the student is a non-Buddhist; the tendency for having SAD dramatically increases. Due to positive coefficient (0.16) and odds ratio (1.18), OGPA also contribute positively for having SAD among students. On the other hand, degree class has a small negative coefficient (-0.08) indicating SAD decreases slightly with increment of the degree class as seen in Table 6 . With the increment of income SAD tends to decrease as suggested by a negative coefficient of -0.26 . As shown in bold fonts in table 6, the academic stressors 2,3,4,6,7,9,10,12,14 and environmental stressors 1,2,3,4,6,7,9 and 11 have contributed positively for the prevalence of SAD in students and thus can be considered as risk factors for SAD.

Factors contributing for Depression. Binary logistic regression coefficients and odds ratios for each of the predictors of Depression is given in Table 7. 
Table 7: Binary logistic regression coefficient and odds ratio table for predicting Depression

\begin{tabular}{|l|l|l||l|l|l|}
\hline Predictor & Coefficient & $\begin{array}{l}\text { Odds } \\
\text { ratio }\end{array}$ & Predictor & Coefficient & $\begin{array}{l}\text { Odds } \\
\text { ratio }\end{array}$ \\
\hline Gender & 0.97 & 2.63 & Age & 0.82 & 2.28 \\
\hline $\begin{array}{l}\text { Civil } \\
\text { status }\end{array}$ & -21.47 & 0.00 & Ethnicity & -1.83 & 0.16 \\
\hline Religion & 1.10 & 3.02 & $\begin{array}{l}\text { Academic } \\
\text { year }\end{array}$ & -0.35 & 0.7 \\
\hline $\begin{array}{l}\text { current } \\
\text { OGPA }\end{array}$ & -0.39 & 0.68 & $\begin{array}{l}\text { degree } \\
\text { class }\end{array}$ & -0.17 & 0.85 \\
\hline Income & 0.14 & 1.15 & AS1 & -0.68 & 0.51 \\
\hline AS2 & -0.28 & 0.75 & AS3 & 0.31 & 1.37 \\
\hline AS4 & 0.29 & 1.34 & AS5 & -0.28 & 0.76 \\
\hline AS6 & 0.23 & 1.26 & AS7 & 0.15 & 1.16 \\
\hline AS8 & -0.99 & 0.37 & AS9 & 0.63 & 1.89 \\
\hline AS10 & 0.16 & 1.17 & AS11 & -0.24 & 0.79 \\
\hline AS12 & -0.53 & 0.59 & AS13 & 0.93 & 2.53 \\
\hline AS14 & -0.05 & 0.95 & ES1 & -0.31 & 0.73 \\
\hline ES2 & 1.03 & 2.81 & ES3 & 0.06 & 1.07 \\
\hline ES4 & 0.32 & 1.37 & ES5 & -0.36 & 0.70 \\
\hline ES6 & -0.14 & 0.87 & ES7 & 0.32 & 1.38 \\
\hline ES8 & -0.4 & 0.67 & ES9 & -0.03 & 0.97 \\
\hline ES10 & -0.41 & 0.66 & ES11 & -0.01 & 0.99 \\
\hline
\end{tabular}

As seen in Table 7, BLR yields a coefficient of 0.97 and odds ratio of 2.63 for the gender concluding that there is $163 \%$ higher chance for finding Depression in males than females. Probability of finding depression seems to increase with the increment of age as coefficient being positive (0.82) and having odds ratio of 2.28. However with academic year, the probability of finding depression decreases by $30 \%$. Depression is found in unmarried students resulting a large negative coefficient. As odds ratio for ethnicity is -1.83 there is less possibility of occurring depression when the race is not Sinhalese. A positive coefficient (1.10) in religion with a odds ratio of 3.02 indicates that when the student is a non-Buddhist; the tendency for having depression increases. OGPA and degree class contribute negatively for having depression among students suggested by negative coefficients and less than 1 odds ratios as seen in Table 7 . With the increment of family income, there is high chance for the increment of Depression as suggested by a coefficient of 0.14 and odds ratio of 1.15. As shown in bold fonts in table 7, the academic stressors 3,4,6,7,9,10,13 and environmental stressors 2,3,4,7 have contributed positively for the prevalence of depression in students and thus can be considered as risk factors for depression.

Factors contributing for $B A D$. Binary logistic regression coefficients and odds ratios for each of the predictors of $\mathrm{BAD}$ is given in Table 8.

Table 8: Binary logistic regression coefficient and odds ratio table for predicting BAD

\begin{tabular}{|l|l|l||l|l|l|}
\hline Predictor & Coefficient & $\begin{array}{l}\text { Odds } \\
\text { ratio }\end{array}$ & Predictor & Coefficient & $\begin{array}{l}\text { Odds } \\
\text { ratio }\end{array}$ \\
\hline Gender & 37.57 & $2.07 \mathrm{E} 16$ & Age & -6 & 0.00 \\
\hline $\begin{array}{l}\text { Civil } \\
\text { status }\end{array}$ & 248.72 & $1.04 \mathrm{E} 108$ & Ethnicity & -28.77 & 0.00 \\
\hline Religion & 14.58 & $2.14 \mathrm{E} 06$ & $\begin{array}{l}\text { Academii } \\
\text { year }\end{array}$ & 8.38 & $4.38 \mathrm{E} 03$ \\
\hline $\begin{array}{l}\text { current } \\
\text { OGPA }\end{array}$ & 8.54 & $5.11 \mathrm{E} 03$ & $\begin{array}{l}\text { degree } \\
\text { class }\end{array}$ & -9.6 & 0.0 \\
\hline Income & 14.45 & $1.88 \mathrm{E} 06$ & AS1 & -32.72 & 0.00 \\
\hline AS2 & -15.97 & 0.00 & AS3 & -22.71 & 0.00 \\
\hline AS4 & 6.15 & 469 & AS5 & 0.94 & 2.56 \\
\hline AS6 & 16.5 & $1.46 \mathrm{E} 07$ & AS7 & -21.71 & 0.00 \\
\hline AS8 & 6.8 & 902 & AS9 & 12.46 & $2.58 \mathrm{E} 05$ \\
\hline AS10 & 0.13 & 1.14 & AS11 & 8.65 & $5.70 \mathrm{E} 03$ \\
\hline AS12 & -5.83 & 0.00 & AS13 & -4.18 & 0.02 \\
\hline AS14 & 8.19 & $3.60 \mathrm{E} 03$ & ES1 & 0.8 & 2.23 \\
\hline ES2 & 5.04 & 155 & ES3 & 11.73 & $1.24 \mathrm{E} 05$ \\
\hline ES4 & -14.79 & 0.00 & ES5 & 0.42 & 1.52 \\
\hline ES6 & -4.30 & 0.01 & ES7 & -6.63 & 0.00 \\
\hline ES8 & 2.52 & 12.4 & ES9 & -30.02 & 0.00 \\
\hline ES10 & 5.41 & 224.02 & ES11 & 3.54 & 34.57 \\
\hline
\end{tabular}


As seen in Table 8, BLR yields a coefficient of 37.57 and odds ratio of 2.07E16 for the gender concluding that there is very higher chance for finding BAD in males than females. Probability of finding BAD seems to reduce with the increment of age as coefficient being negative (-6) and having odds ratio of 0.00 . However with academic year, the probability of finding BAD increases by very large margin due to coefficient being 8.38 with odds ratio 438 . BAD is highly likely to be found in married students due to the large positive coefficient. As odds ratio for ethnicity is -28.77 , there is high possibility of occurring BAD when the race is Sinhalese. A positive coefficient (14.58) in religion with a odds ratio of 2.14E06 indicates that when the student is a non-Buddhist; the tendency for having BAD increases. OGPA also contribute positively for having BAD among students suggested by positive coefficients and large odds ratios as seen in Table 8 . With the increment of degree class, BAD is less likely to be found due to the negative coefficient and zero odds ratio suggesting that $\mathrm{BAD}$ is almost found in general degree holders. With increment of income, there is high chance of finding BAD due to positive coefficient of 14.45 and odds ratio of 1.88E06. As shown in bold fonts in table 8 , the academic stressors 4,5,6,8,9,10,11,14 and environmental stressors 1,2,3,5,8,10 and 11 have contributed positively for the prevalence of BAD in students and thus can be considered as risk factors for BAD.

Factors contributing for DD. Binary logistic regression coefficients and odds ratios for each of the predictors of Agoraphobia is given in Table 9.

Table 9: Binary logistic regression coefficient and odds ratio table for predicting DD

\begin{tabular}{|l|l|l||l|l|l|}
\hline Predictor & Coefficient & $\begin{array}{l}\text { Odds } \\
\text { ratio }\end{array}$ & Predictor & Coefficient & $\begin{array}{l}\text { Odds } \\
\text { ratio }\end{array}$ \\
\hline Gender & 32.44 & $1.2 \mathrm{E} 14$ & Age & -15.43 & $2.0 \mathrm{E}-07$ \\
\hline $\begin{array}{l}\text { Civil } \\
\text { status }\end{array}$ & 260.48 & $1.3 \mathrm{E} 113$ & Ethnicity & 43.23 & $5.9 \mathrm{E}+18$ \\
\hline Religion & -11.03 & $1.6 \mathrm{E}-05$ & $\begin{array}{l}\text { Academii } \\
\text { year }\end{array}$ & 61.7 & $6.2 \mathrm{E} 26$ \\
\hline $\begin{array}{l}\text { current } \\
\text { OGPA }\end{array}$ & -46.41 & $7.0 \mathrm{E}-21$ & $\begin{array}{l}\text { degree } \\
\text { class }\end{array}$ & 16.31 & $1.2 \mathrm{E} 07$ \\
\hline Income & 7.57 & $1.9 \mathrm{E} 03$ & AS1 & -8.3 & $2.5 \mathrm{E}-04$ \\
\hline AS2 & -35.88 & $2.6 \mathrm{E}-16$ & AS3 & 5.92 & 370 \\
\hline AS4 & 37.1 & $1.3 \mathrm{E} 16$ & AS5 & 10.06 & $2.3 \mathrm{E} 04$ \\
\hline AS6 & 19.63 & $3.3 \mathrm{E} 08$ & AS7 & -8.6 & $1.8 \mathrm{E}-04$ \\
\hline AS8 & 12.93 & $4.1 \mathrm{E} 05$ & AS9 & 32.29 & $1.1 \mathrm{E} 14$ \\
\hline AS10 & -11.65 & $8.7 \mathrm{E}-06$ & AS11 & -13.39 & $1.5 \mathrm{E}-06$ \\
\hline AS12 & -39.79 & $5.2 \mathrm{E}-18$ & AS13 & 30.35 & $1.5 \mathrm{E} 13$ \\
\hline AS14 & 24.66 & $5.1 \mathrm{E} 10$ & ES1 & 0.00 & 1.00 \\
\hline ES2 & 0.95 & 2.6 & ES3 & 8.85 & 7000 \\
\hline ES4 & 2.43 & 11 & ES5 & -24.11 & $3.4 \mathrm{E}-11$ \\
\hline ES6 & -18.59 & $8.5 \mathrm{E}-09$ & ES7 & -3.22 & 0.04 \\
\hline ES8 & 21.04 & $1.4 \mathrm{E} 09$ & ES9 & -22.48 & $1.7 \mathrm{E}-10$ \\
\hline ES10 & 9.41 & $1.2 \mathrm{E} 04$ & ES11 & -21.80 & $3.4 \mathrm{E}-10$ \\
\hline
\end{tabular}

As seen in Table 9, BLR yields a coefficient of 32.44 and odds ratio of 1.2E14 for the gender concluding that there is very higher chance for finding DD in males than females. Probability of finding DD seems to reduce drastically with the increment of age as coefficient being negative (-15.43) and having odds ratio of 2.0E-07. However with academic year, the probability of finding DD increases by a very large margin as suggested by high odds ratio of 6.2E26. DD is more likely to be found in married students as suggested by the large positive coefficient (260.48). As odds ratio for ethnicity is 5.9E18, there is high possibility of occurring DD when the race is not Sinhalese. A negative coefficient (-11.03) in religion with a odds ratio of 1.6E-05 indicates that when the student is a non-Buddhist; the tendency for having DD decreases drastically. OGPA seems to contribute negatively for having DD among students suggested by negative coefficient and large odds ratio as seen in Table 9. Degree class has a positive relationship for the DD as suggested by the positive coefficient of 16.31. Increment of family income also contribute positively for the DD since the corresponding coefficient is 7.57. As shown in bold fonts in table 9, the academic stressors $3,4,5,6,8,9,13,14$ and environmental stressors 2,3,4,8 and 10 have contributed positively for the prevalence of DD in students and thus can be considered as risk factors for DD.

Factors contributing for ED. Binary logistic regression coefficients and odds ratios for each of the predictors of ED is given in Table 10. 


\begin{tabular}{|l|l|l||l|l|l|}
\hline Predictor & Coefficient & $\begin{array}{l}\text { Odds } \\
\text { ratio }\end{array}$ & Predictor & Coefficient & $\begin{array}{l}\text { Odds } \\
\text { ratio }\end{array}$ \\
\hline Gender & 0.70 & 2.02 & Age & 0.03 & 1.03 \\
\hline $\begin{array}{l}\text { Civil } \\
\text { status }\end{array}$ & -19.54 & 0.00 & Ethnicity & -0.18 & 0.84 \\
\hline Religion & 0.71 & 2.03 & $\begin{array}{l}\text { Academic } \\
\text { year }\end{array}$ & 0.36 & 1.43 \\
\hline $\begin{array}{l}\text { current } \\
\text { OGPA }\end{array}$ & -0.55 & 0.57 & $\begin{array}{l}\text { degree } \\
\text { class }\end{array}$ & 0.08 & 1.09 \\
\hline Income & 0.10 & 1.10 & AS1 & -0.01 & 0.99 \\
\hline AS2 & 0.23 & 1.26 & AS3 & 0.41 & 1.50 \\
\hline AS4 & -0.41 & 0.66 & AS5 & 0.05 & 1.06 \\
\hline AS6 & -0.03 & 0.97 & AS7 & -0.03 & 0.97 \\
\hline AS8 & 0.2 & 1.22 & AS9 & 0.36 & 1.44 \\
\hline AS10 & 0.11 & 1.11 & AS11 & 0.02 & 1.02 \\
\hline AS12 & -0.52 & 0.60 & AS13 & -0.06 & 0.94 \\
\hline AS14 & 0.11 & 1.12 & ES1 & 0.47 & 1.59 \\
\hline ES2 & 0.45 & 1.57 & ES3 & -0.22 & 0.8 \\
\hline ES4 & -0.09 & 0.91 & ES5 & 0.11 & 1.12 \\
\hline ES6 & 0.24 & 1.27 & ES7 & 0.41 & 1.51 \\
\hline ES8 & 0.12 & 1.13 & ES9 & -0.97 & 0.38 \\
\hline ES10 & -0.23 & 0.80 & ES11 & -0.44 & 0.64 \\
\hline
\end{tabular}

As seen in Table 10, BLR yields a coefficient of 0.70 and odds ratio of 2.02 for the gender concluding that there is $102 \%$ higher chance for finding ED in males than females. Probability of finding ED seems to slightly (by $3 \%$ ) increase with the increment of age as coefficient being positive (0.03) and having odds ratio of 1.03 . This is true for the academic year which the probability of finding ED increases by $43 \%$. ED is found in unmarried students resulting a large negative coefficient. As odds ratio for ethnicity is 0.84 there is less possibility of occurring ED when the race is not Sinhalese. A positive coefficient (0.71) in religion with a odds ratio of 2.03 indicates that when the student is a non-Buddhist; the tendency for having ED increases. Current OGPA is having a negative relationship with ED as proved by its negative coefficient of -0.55 . Expected degree class contributes positively for having ED among students suggested by positive coefficient (0.08) and odds ratio (1.09) as seen in Table 10. Further, the increment of family income class increases the chance of getting an ED due to coefficient of 0.10. As shown in bold fonts in table 10 , the academic stressors 2,3,5, 8, 9, 10,11,14 and environmental stressors 1,2,5,6,7 and 8 have contributed positively for the prevalence of ED in students and thus can be considered as risk factors for ED.

Factors contributing for $O C D$. Binary logistic regression coefficients and odds ratios for each of the predictors of OCD is given in Table 11.

Table 11: Binary logistic regression coefficient and odds ratio table for predicting OCD

\begin{tabular}{|l|l|l||l|l|l|}
\hline Predictor & Coefficient & $\begin{array}{l}\text { Odds } \\
\text { ratio }\end{array}$ & Predictor & Coefficient & $\begin{array}{l}\text { Odds } \\
\text { ratio }\end{array}$ \\
\hline Gender & 0.11 & 1.12 & Age & -0.02 & 0.98 \\
\hline $\begin{array}{l}\text { Civil } \\
\text { status }\end{array}$ & -18.69 & 0.00 & Ethnicity & -0.46 & 0.63 \\
\hline Religion & 0.53 & 1.70 & $\begin{array}{l}\text { Academid } \\
\text { year }\end{array}$ & 0.56 & 1.76 \\
\hline $\begin{array}{l}\text { current } \\
\text { OGPA }\end{array}$ & -1.75 & 0.17 & $\begin{array}{l}\text { degree } \\
\text { class }\end{array}$ & -0.38 & 0.68 \\
\hline Income & 0.12 & 1.12 & AS1 & -0.49 & 0.62 \\
\hline AS2 & -0.44 & 0.65 & AS3 & 0.28 & 1.32 \\
\hline AS4 & 0.39 & 1.47 & AS5 & -0.25 & 0.78 \\
\hline AS6 & 0.46 & 1.58 & AS7 & -0.24 & 0.79 \\
\hline AS8 & -0.24 & 0.79 & AS9 & 0.06 & 1.06 \\
\hline AS10 & 0.28 & 1.32 & AS11 & -0.05 & 0.95 \\
\hline AS12 & -1.09 & 0.33 & AS13 & 0.34 & 1.41 \\
\hline AS14 & 0.11 & 1.11 & ES1 & -0.17 & 0.85 \\
\hline ES2 & 0.38 & 1.47 & ES3 & -0.04 & 0.96 \\
\hline ES4 & -0.14 & 0.87 & ES5 & -0.44 & 0.64 \\
\hline ES6 & -0.27 & 0.76 & ES7 & 0.71 & 2.03 \\
\hline ES8 & 0.18 & 1.20 & ES9 & 0.15 & 1.16 \\
\hline ES10 & -0.14 & 0.87 & ES11 & -0.84 & 0.43 \\
\hline
\end{tabular}


As seen in Table 11, BLR yields a coefficient of 0.11 and odds ratio of 1.12 for the gender concluding that there is $12 \%$ higher chance for finding OCD in males than females. Probability of finding OCD seems to reduce with the increment of age as coefficient being negative (-0.02) and having odds ratio of 0.98 . However with academic year, the probability of finding OCD increases by $76 \%$ OCD is found in unmarried students resulting a large negative coefficient. As odds ratio for ethnicity is 0.63 , there is less possibility of occurring OCD when the race is not Sinhalese. A positive coefficient (0.53) in religion with a odds ratio of 1.70 indicates that when the student is a non-Buddhist; the tendency for having OCD increases. Current OGPA and degree class contribute negatively for having OCD among students suggested by negative coefficients and less than one odds ratios as seen in Table 11. Presence of OCD increases with the increment of family income as the coefficient is positive (0.12). As shown in bold fonts in table 11, the academic stressors $3,4,6,9,10,13,14$ and environmental stressors $2,7,8$ and 9 have contributed positively for the prevalence of OCD in students and thus can be considered as risk factors for OCD.

Factors contributing for Schizophrenia. Binary logistic regression coefficients and odds ratios for each of the predictors of Schizophrenia is given in Table 12.

Table 12: Binary logistic regression coefficient and odds ratio table for predicting Schizophrenia

\begin{tabular}{|l|l|l||l|l|l|}
\hline Predictor & Coefficient & $\begin{array}{l}\text { Odds } \\
\text { ratio }\end{array}$ & Predictor & Coefficient & $\begin{array}{l}\text { Odds } \\
\text { ratio }\end{array}$ \\
\hline Gender & -1.42 & 0.24 & Age & -0.16 & 0.85 \\
\hline $\begin{array}{l}\text { Civil } \\
\text { status }\end{array}$ & -19.41 & 0.00 & Ethnicity & 1.23 & 3.41 \\
\hline Religion & -0.63 & 0.53 & $\begin{array}{l}\text { Academii } \\
\text { year }\end{array}$ & -0.24 & 0.79 \\
\hline $\begin{array}{l}\text { current } \\
\text { OGPA }\end{array}$ & -0.31 & 0.73 & $\begin{array}{l}\text { degree } \\
\text { class }\end{array}$ & 0.04 & 1.05 \\
\hline Income & 0.32 & 1.38 & AS1 & 0.25 & 1.29 \\
\hline AS2 & 0.10 & 1.11 & AS3 & -0.09 & 0.92 \\
\hline AS4 & -0.18 & 0.83 & AS5 & -0.45 & 0.64 \\
\hline AS6 & 0.08 & 1.08 & AS7 & -0.15 & 0.86 \\
\hline AS8 & -0.17 & 0.84 & AS9 & -0.06 & 0.94 \\
\hline AS10 & -0.17 & 0.84 & AS11 & 0.83 & 2.29 \\
\hline AS12 & 0.03 & 1.03 & AS13 & -0.08 & 0.92 \\
\hline AS14 & 0.62 & 1.86 & ES1 & 0.60 & 1.82 \\
\hline ES2 & 0.46 & 1.58 & ES3 & 0.20 & 1.22 \\
\hline ES4 & 0.23 & 1.26 & ES5 & 0.35 & 1.41 \\
\hline ES6 & -0.59 & 0.56 & ES7 & -0.18 & 0.84 \\
\hline ES8 & 0.27 & 1.31 & ES9 & -0.88 & 0.42 \\
\hline ES10 & -0.13 & 0.87 & ES11 & -0.04 & 0.96 \\
\hline
\end{tabular}

As seen in Table 12, BLR yields a coefficient of -1.42 and odds ratio of 0.24 for the gender concluding that there is $76 \%$ higher chance for finding Schizophrenia in females than males. Probability of finding Schizophrenia seems to reduce with the increment of age as coefficient being negative $(-0.16)$ and having odds ratio of 0.85 . Also with academic year, the probability of finding Schizophrenia decreases by $21 \%$. Schizophrenia is found in unmarried students resulting a large negative coefficient. As odds ratio for ethnicity is 3.41 there is high possibility of occurring Schizophrenia when the race is not Sinhalese. A negative coefficient (-0.63) in religion with a odds ratio of 0.53 indicates that when the student is a non-Buddhist; the tendency for having Schizophrenia decreases. Current OGPA also contribute negatively for having Schizophrenia among students suggested by negative coefficient $(-0.31)$ and odds ratio of 0.73 as seen in Table 12. Schizophrenia tends to increase by $5 \%$ with increment of the degree class as suggested by odds ratio of 1.05. Further, increment of family income also tends to increase the chance of having Schizophrenia in students. As shown in bold fonts in table 12, the academic stressors 1,2,6,11,12,14 and environmental stressors 1,2,3,4,5 and 8 have contributed positively for the prevalence of Schizophrenia in students and thus can be considered as risk factors for Schizophrenia.

Factors contributing for Paranoia. Binary logistic regression coefficients and odds ratios for each of the predictors of Paranoia is given in Table 13. 


\begin{tabular}{|l|l|l||l|l|l|}
\hline Predictor & Coefficient & $\begin{array}{l}\text { Odds } \\
\text { ratio }\end{array}$ & Predictor & Coefficient & $\begin{array}{l}\text { Odds } \\
\text { ratio }\end{array}$ \\
\hline Gender & -0.25 & 0.78 & Age & 0.05 & 1.06 \\
\hline $\begin{array}{l}\text { Civil } \\
\text { status }\end{array}$ & -17.48 & 0.00 & Ethnicity & -2.43 & 0.09 \\
\hline Religion & 3.03 & 20.61 & $\begin{array}{l}\text { Academid } \\
\text { year }\end{array}$ & -0.02 & 0.98 \\
\hline $\begin{array}{l}\text { current } \\
\text { OGPA }\end{array}$ & 0.41 & 1.51 & $\begin{array}{l}\text { degree } \\
\text { class }\end{array}$ & 0.02 & 1.02 \\
\hline Income & 0.26 & 1.30 & AS1 & -0.4 & 0.67 \\
\hline AS2 & -0.65 & 0.52 & AS3 & 0.11 & 1.11 \\
\hline AS4 & -0.09 & 0.92 & AS5 & 0.21 & 1.23 \\
\hline AS6 & 0.77 & 2.16 & AS7 & 0.12 & 1.13 \\
\hline AS8 & -0.01 & 0.99 & AS9 & -0.24 & 0.78 \\
\hline AS10 & 0.78 & 2.18 & AS11 & 0.33 & 1.39 \\
\hline AS12 & -1.29 & 0.28 & AS13 & 0.66 & 1.93 \\
\hline AS14 & -0.12 & 0.89 & ES1 & 0.13 & 1.13 \\
\hline ES2 & 0.15 & 1.16 & ES3 & -0.2 & 0.82 \\
\hline ES4 & 0.19 & 1.21 & ES5 & -0.55 & 0.58 \\
\hline ES6 & -0.3 & 0.74 & ES7 & 0.63 & 1.88 \\
\hline ES8 & -0.59 & 0.55 & ES9 & -0.78 & 0.46 \\
\hline ES10 & -0.42 & 0.66 & ES11 & 0.12 & 1.13 \\
\hline
\end{tabular}

As seen in Table 13, BLR yields a coefficient of -0.25 and odds ratio of 0.78 for the gender concluding that there is $22 \%$ lesser chance for finding paranoia in males than females. Probability of finding paranoia seems to increase with the increment of age as coefficient being positive (0.05) and having odds ratio of 1.06. However with academic year, the probability of finding paranoia decreases by $2 \%$. Paranoia is found in unmarried students resulting a large negative coefficient. As odds ratio for ethnicity is 0.09 there is less possibility of occurring paranoia when the race is not Sinhalese. A positive coefficient (3.03) in religion with a odds ratio of 20.61 indicates that when the student is a non-Buddhist; the tendency for having paranoia increases dramatically. Current OGPA and degree class also contribute positively for having paranoia among students suggested by positive coefficients and large odds ratios as seen in Table 13. Increment of the family income also contribute positively for the presence of Paranoia in students as suggested by the positive coefficient (0.26). As shown in bold fonts in table 13, the academic stressors 3,5,6,7,10,11,13 and environmental stressors 1,2,4,7 and 11 have contributed positively for the prevalence of paranoia in students and thus can be considered as risk factors for paranoia.

Factors contributing for PTSD. Binary logistic regression coefficients and odds ratios for each of the predictors of PTSD is given in Table 14.

Table 14: Binary logistic regression coefficient and odds ratio table for predicting PTSD

\begin{tabular}{|l|l|l||l|l|l|}
\hline Predictor & Coefficient & $\begin{array}{l}\text { Odds } \\
\text { ratio }\end{array}$ & Predictor & Coefficient & $\begin{array}{l}\text { Odds } \\
\text { ratio }\end{array}$ \\
\hline Gender & 15.0 & $3.25 E 06$ & Age & -3.50 & 0.03 \\
\hline $\begin{array}{l}\text { Civil } \\
\text { status }\end{array}$ & 34.36 & $8.36 E 14$ & Ethnicity & 3.19 & 24.26 \\
\hline Religion & -3.47 & 0.03 & $\begin{array}{l}\text { Academid } \\
\text { year }\end{array}$ & 1.47 & 4.34 \\
\hline $\begin{array}{l}\text { current } \\
\text { OGPA }\end{array}$ & 3.17 & 23.83 & $\begin{array}{l}\text { degree } \\
\text { class }\end{array}$ & -3.37 & 0.03 \\
\hline Income & 0.78 & 2.19 & AS1 & 0.44 & 1.55 \\
\hline AS2 & -1.56 & 0.21 & AS3 & -4.28 & 0.01 \\
\hline AS4 & 4.47 & 87.7 & AS5 & -10.01 & 0.00 \\
\hline AS6 & 9.89 & $1.97 E 04$ & AS7 & 3.20 & 24.51 \\
\hline AS8 & -7.81 & 0.00 & AS9 & 11.81 & $1.35 \mathrm{E} 05$ \\
\hline AS10 & 8.9 & $7.36 E 03$ & AS11 & -4.39 & 0.01 \\
\hline AS12 & -3.51 & 0.03 & AS13 & 3.46 & 31.68 \\
\hline AS14 & 1.62 & 5.03 & ES1 & -2.72 & 0.07 \\
\hline ES2 & 5.77 & 319.23 & ES3 & -3.14 & 0.04 \\
\hline ES4 & -0.8 & 0.45 & ES5 & -0.79 & 0.45 \\
\hline ES6 & 0.08 & 1.08 & ES7 & -2.59 & 0.08 \\
\hline ES8 & 0.97 & 2.65 & ES9 & 4.76 & 116.48 \\
\hline ES10 & 1.76 & 5.83 & ES11 & -1.52 & 0.22 \\
\hline
\end{tabular}


As seen in Table 14, BLR yields a coefficient of 15.0 and odds ratio of 3.25E06 for the gender concluding that there is a very higher chance for finding PTSD in males than females. Probability of finding PTSD seems to reduce with the increment of age as coefficient being negative (-3.50) and having odds ratio of 0.03 . However with academic year, the probability of finding PTSD increases by $334 \%$. PTSD is found more in married students resulting a large positive coefficient. As odds ratio for ethnicity is 24.26 there is very possibility of occurring PTSD when the race is not Sinhalese. A negative coefficient (-3.47) in religion with a odds ratio of 0.03 indicates that when the student is a non-Buddhist; the tendency for having PTSD decreases. Current OGPA also contributes positively for having PTSD among students suggested by positive coefficients and large odds ratios as seen in Table 14. But, the increment of the degree class causes PSTD presence to decrease suggested by negative coefficient of -3.37 . Increment of family income class tends to increase the probability of finding PTSD. As shown in bold fonts in table 14, the academic stressors $1,4,6,7,9,10,13$ and environmental stressors 2,6,8,9,10 have contributed positively for the prevalence of PTSD in students and thus can be considered as risk factors for PTSD.

Factors contributing for Psychosis. Binary logistic regression coefficients and odds ratios for each of the predictors of Psychosis is given in Table 15.

Table 15: Binary logistic regression coefficient and odds ratio table for predicting Psychosis

\begin{tabular}{|l|l|l||l|l|l|}
\hline Predictor & Coefficient & $\begin{array}{l}\text { Odds } \\
\text { ratio }\end{array}$ & Predictor & Coefficient & $\begin{array}{l}\text { Odds } \\
\text { ratio }\end{array}$ \\
\hline Gender & 0.51 & 1.67 & Age & -0.06 & 0.94 \\
\hline $\begin{array}{l}\text { Civil } \\
\text { status }\end{array}$ & -19.12 & 0.00 & Ethnicity & -0.64 & 0.53 \\
\hline Religion & 0.83 & 2.30 & $\begin{array}{l}\text { Academii } \\
\text { year }\end{array}$ & 0.20 & 1.23 \\
\hline $\begin{array}{l}\text { current } \\
\text { OGPA }\end{array}$ & -0.26 & 0.77 & $\begin{array}{l}\text { degree } \\
\text { class }\end{array}$ & 0.15 & 1.17 \\
\hline Income & -0.02 & 0.98 & AS1 & -0.05 & 0.95 \\
\hline AS2 & -0.63 & 0.53 & AS3 & 0.44 & 1.56 \\
\hline AS4 & -0.18 & 0.83 & AS5 & -0.24 & 0.78 \\
\hline AS6 & 0.88 & 2.41 & AS7 & 0.09 & 1.09 \\
\hline AS8 & -0.93 & 0.39 & AS9 & -0.2 & 0.82 \\
\hline AS10 & 0.09 & 1.10 & AS11 & 0.40 & 1.49 \\
\hline AS12 & -0.05 & 0.96 & AS13 & 0.41 & 1.51 \\
\hline AS14 & 0.01 & 1.01 & ES1 & 0.32 & 1.37 \\
\hline ES2 & -0.05 & 0.95 & ES3 & 0.22 & 1.25 \\
\hline ES4 & 0.41 & 1.50 & ES5 & -0.57 & 0.56 \\
\hline ES6 & -0.14 & 0.87 & ES7 & -0.15 & 0.86 \\
\hline ES8 & 0.11 & 1.11 & ES9 & -0.47 & 0.63 \\
\hline ES10 & 0.15 & 1.16 & ES11 & 0.29 & 1.34 \\
\hline
\end{tabular}

As seen in Table 15, BLR yields a coefficient of 0.51 and odds ratio of 1.67 for the gender concluding that there is $67 \%$ higher chance for finding psychosis in males than females. Probability of finding psychosis seems to reduce with the increment of age as coefficient being negative (-0.06) and having odds ratio of 0.94 . However with academic year, the probability of finding psychosis increases by $23 \%$. Psychosis is found more in unmarried students resulting a large negative coefficient (-19.12). As odds ratio for ethnicity is 0.53 , there is less possibility of occurring psychosis when the race is not Sinhalese. A positive coefficient $(0.83)$ in religion with a odds ratio of 2.30 indicates that when the student is a non-Buddhist; the tendency for having psychosis increases. Current OGPA increment tends to decrease the probability of the presence of Psychosis in student as suggested by the negative coefficient of -0.26 .Degree class contributes positively for having psychosis among students suggested by positive coefficients and large odds ratios as seen in Table 15. Increment of family income class tends to decrease the prevalence of Psychosis among students. As shown in bold fonts in table 15, the academic stressors 3,6,7,10,11,13, 14 and environmental stressors 1,3,4,8,10,11 have contributed positively for the prevalence of psychosis in students and thus can be considered as risk factors for psychosis.

\section{Discussion}

In this section, we will discuss the cross analysis of factors causing psychiatric illnesses among students in order to identify the risk factors for causing psychiatric illnesses. For 9 psychiatric illnesses, the prevalence was higher for the Male gender. Only for PD, SAD, Schizophrenia and Paranoia; the probability of finding the illness were higher among the Feminine gender. Thus, the risk factor $(\mathrm{R})$ for gender is $69 \%$. In 
almost all diseases, except for the cases of ED and depression, the possibility of prevalence of the psychiatric illness has reduced with the increment of age. Thus, the risk factor for being in a lesser age group is $77 \%$. Age is not directly related with the academic year because for a given academic year, there can be students with multiple ages such as first shy students, second shy students, third shy students, repeat or batch missed students etc. Increment of academic year showed positive signs for chances of prevalence of psychiatric illness except for the cases of depression, Schizophrenia and Paranoia. Thus, the risk factor for being in higher academic year is $77 \%$. When the students go high in academic years, their workload and expected cognitive skills increase; so, it is justifiable why for most of the illnesses, advancement of the academic year contributes for finding psychiatric illnesses more. The prevalence of psychiatric illnesses was more for unmarried students for most of the psychiatric illnesses except for Agoraphobia, BAD, DD, and PTSD. Thus, the Risk Factor for being unmarried is $70 \%$. This can be argued due to the fact that most of the students are unmarried. Most of the psychiatric illnesses were found in Sinhalese except for the cases of Agoraphobia, PD, DD, Schizophrenia and PTSD. Thus, the risk factor for being a Sinhalese is $72 \%$. This can also because of the fact that majority of the population were Sinhalese. However, even though most of the student population were Buddhists, only 4 psychiatric illnesses (Agoraphobia, DD, Schizophrenia, PTSD) were more probable among Buddhists. Thus, the risk factor for being a non-Buddhist is $69 \%$. Both current OGPA and expected degree class affected for the presence of psychiatric illnesses in a mixed manner. For some diseases they had a positive relationship and vice versa. But it was very evident that GAD and Paranoia were probable in those students with a high OGPA who are expecting a high-class degree. Further, for those students expecting a high-class degree; DD, ED, Schizophrenia and Psychosis were more probable. Surprisingly, the increment of family income or in other terms students from rich family backgrounds have a higher probability of prevalence of psychiatric illnesses than students from poor families except for the cases of GAD, SAD and Psychosis. Thus, the risk factor for being in a high-income family class is $77 \%$. This can be argued due to the fact that richer students who have been accustomed for a comfortable and caring life from their childhood being less tolerable for the stressors; once become students with academic and environmental stressors tend to suffer from psychiatric illnesses.

The factor "being satisfied in the degree program" negatively affects the presence of psychiatric illnesses except for the cases of PD, Schizophrenia and PTSD. So, it is very clear that students those who are less satisfied about the degree program tends to suffer from many psychiatric illnesses such as Depression, BAD, agoraphobia etc. Next, conventional written examinations do not seem to contribute much positively for the prevalence of mental illnesses except for the cases of SAD, ED and Schizophrenia. On the other hand, online written end semester/year end exams contribute positively for the prevalence of many psychiatric illnesses except for the cases of GAD, BAD, Schizophrenia and PTSD. Thus, the risk factor for facing online written examination is $69 \%$. This proves that online mode of evaluation tends to increase the psychiatric illnesses among students. Oral examinations (viva) also tend to increase mental illnesses except for the cases of ED, Schizophrenia, Paranoia and psychosis. Thus, the risk factor for oral examination is also $69 \%$. Oral presentation does not seem to contribute positively for the prevalence of mental illnesses except for the cases of BAD, DD, ED and Paranoia. Individual self-learning tends to increase the prevalence of almost all the mental illnesses except ED. Thus, the risk factor for individual self-learning is very high as $92 \%$. It is difficult to predict whether participation for a lecture tends to increase the mental illnesses in overall because it has mixed impact on the prevalence of illnesses. Participation for online lecture does not increase the tendency for occurrence of psychiatric illnesses in most cases except for the cases of Agoraphobia, BAD, ED, DD. Active learning tends to increase most of the prevalence of mental illnesses except for the cases of Schizophrenia, Paranoia and psychosis. Thus, the risk factor for active learning is $77 \%$. Research and project development work also tends to increase the prevalence of most of the mental illnesses except for the cases of DD and Schizophrenia. Thus, the risk factor for research and development work is $85 \%$. It is difficult to predict the overall effect of the online quiz as it contributes in both ways (presence or absence) of psychiatric illnesses. Physical in-class tests do not seem to contribute for the presence of most of the psychiatric illnesses except for the cases of PD, SAD and Schizophrenia. Practical demonstrations also tend to increase the presence of most of the mental illnesses except for the cases of SAD, BAD, ED and Schizophrenia. Thus, the risk factor for practical demonstrations is $69 \%$. Industrial/professional/worksite training also contributes positively for the prevalence of most of the psychiatric illnesses except for the cases of GAD, PD, depression and paranoia. Thus, the risk factor for Industrial/professional/worksite training is also $69 \%$.

Prevalence of financial difficulties have also contributed positively for the prevalence of psychiatric illnesses except in cases of Agoraphobia, depression, DD, OCD and PTSD. Thus, the risk factor for financial difficulties is $62 \%$. COVID 19 has very clearly contributed for the prevalence of psychiatric illnesses as only 2 cases (PD and psychosis) were otherwise. Thus, the risk factor for the prevalence of COVID19 is 85 $\%$. Presence of a physical illness also had contributed for the presence of most of the psychiatric illnesses except for the cases of Agoraphobia, ED, OCD, Paranoia and PTSD. Thus, the risk factor for presence of a physical illness is $62 \%$. Relationship problems also clearly contribute for the increment of most of the 
mental illnesses except for the cases of BAD, ED, OCD and PTSD. Thus, the risk factor for the presence of relationship problems is $62 \%$. Bad experience due to ragging was not a risk factor for most of the illnesses but it was a risk factor for the Agoraphobia, PD, BAD, ED and Schizophrenia. This verifies the previously obtained result that for most of the students PTSD is not caused due to ragging. Death or sickness of a close associate was not a risk factor for most of the illnesses except for GAD, SAD, DD, PTSD. Accommodation problems had a mixed effect for the presence or absence of psychiatric illnesses. Problems in the teaching learning process clearly had a positive effect for the presence of most of the psychiatric illnesses except for the cases of GAD, SAD, depression and Paranoia. Thus, the risk factor for problems in teaching learning process is $69 \%$. Troubles in online learning was not a positively contributing factor for most of the psychiatric illnesses except for PD, SAD, OCD and PTSD. Lack of support for psychiatric help had a mixed impact for the presence or absence of psychiatric illnesses. Having less or no time to spend for leisure/sports/music etc. also had a mixed impact for the presence or absence of psychiatric illnesses so overall effect cannot be decided.

\section{Recommendations}

The universities must consider the academic risk factors associated with psychiatric illnesses and design curriculum to reduce the academic risk factors. Further as $61 \%$ of the students mention that they don't receive psychiatric help from the university; authorities must expand resources for providing resources for sports, music, cultural event organizing, provide counseling services and financial support etc.

\section{Conclusion}

All 13 psychiatric illnesses were found in the sample of students with a per disease mean prevalence percentage of 25.92 having a standard deviation of 12.93 despite the prevalence of well-being factors among students and only $8 \%$ are clinically diagnosed. There was no strong correlation between presence of each psychiatric illness; but medium correlation was observed between some pairs of illnesses. Students are mainly using the remedies: relaxation techniques (Music, sports, leisure etc.), support from family and friends, online social networks, mindfulness meditation and online gaming to reduce the psychological distress. Individual risk factors for each of the psychiatric illnesses were identified after a BLRA. Finally, a conclusion on overall risk factors for the presence of a psychiatric illness in general can be derived as follows. Being a male $(R=69 \%)$, lesser age group $(R=77 \%)$, unmarried $(R=70 \%)$, Sinhalese $(R=72 \%)$, NonBuddhist ( $\mathrm{R}=69 \%$ ) and having a high family income class $(\mathrm{R}=77 \%)$ were identified as demographic risk factors for the presence of a psychiatric illness. Being in a high academic year ( $\mathrm{R}=77 \%)$, having to face online written end examination ( $R=69 \%)$, having to face oral examination ( $R=69 \%)$, Individual self-learning $(\mathrm{R}=92 \%)$, active learning involving group work $(\mathrm{R}=77 \%)$, research and development work $(\mathrm{R}=85 \%)$, practical demonstrations $(\mathrm{R}=69 \%)$ and industrial/professional/worksite training ( $\mathrm{R}=69 \%)$ are the academic risk factors contributing positively for the prevalence of psychiatric illnesses. Prevalence of financial difficulties ( $R=62 \%)$, prevalence of COVID19 $(R=85 \%)$, presence of a physical illness ( $R=62 \%)$, presence of relationship problems $(\mathrm{R}=62 \%)$, problems in the teaching-learning process $(\mathrm{R}=69 \%)$ were identified as the environmental risk factors. The level of prevalence of psychiatric illnesses were high as $89 \%$ of the students were suffering from at least one psychiatric illness and $68 \%$ were screened to be psychologically distressed.

\subsection{Limitations}

The case study investigates on the factors, remedies and prevalence of psychiatric illnesses in a Sri Lankan university. The outcomes may vary based on demographic factors in other universities of the world. Standard questionnaires used in the context of this research are used for screening patients for a particular psychiatric illness and for preliminary investigation. Further investigation and a clinical diagnosis by a psychiatrist may be required in order to confirm the presence of a psychiatric illness of a screened patient.

\section{2. author's contributions}

conceptualization - P.A.D.S.N. Wijesekara; methodology - P.A.D.S.N.W.; software- P.A.D.S.N.W.; validation - P.A.D.S.N.W. - formal analysis - P.A.D.S.N.W.; investigation - P.A.D.S.N.W.; resources - P.A.D.S.N.W.; data curation - P.A.D.S.N.W.; writing-original draft preparation - P.A.D.S.N.W. ; writing-review and editing - P.A.D.S.N. Wijesekara; visualization - P.A.D.S.N.W.; supervision - None

\subsection{Acknowledgements}

We acknowledge the contribution of all the participants who filled the questionnaire and responded in time to make this work a success. 


\subsection{Competing interests}

No conflict of interest.

\subsection{Availability of data, code, and other materials}

The datasets analyzed during the current study are not publicly available due ethical reasons but are available from the corresponding author on reasonable request. Datasets are also available for the Journal for reviewing purposes.

\subsection{Consent for publication}

Not applicable

\subsection{Ethical approval and consent to participate}

The present study was approved by the Ethics Review Committee of University of Ruhuna and by the Vice Chancellor. All participants gave their informed consent for participation in the study before filling in the questionnaire.

\subsection{Funding}

This research did not receive any financial support. This was conducted with the expenses of the sole author.

\section{References}

1. Wimberly C.E., Rajapakse H., Park L.P., Price A., Proeschold-Bell R.J. and Østbye T. Mental well-being in Sri Lankan medical students: a cross-sectional study. Psychology, Health \& Medicine, 1-14 (2020)

2. Rathnayake S. and Ekanayaka J. Depression, anxiety, and stress among undergraduate nursing students in a public university in Sri Lanka. International Journal of Caring Sciences.9(3), 1020-1032 (2016)

3. Wickramasinghe N.D., Dissanayake D.S. and Abeywardena G.S. Prevalence and correlates of burnout among collegiate cycle students in Sri Lanka: a school-based cross-sectional study. Child and adolescent psychiatry and mental health. 12(1), 1-11 (2018)

4. Mahees M.T. Stress Among University Undergraduates: A Case study of University of Colombo, Sri Lanka. International Educational Applied Research Journal (IEARJ). 4(05). (2020).

5. Madhusanka A.K.P., Jayasuriya N.U., Ravishanka M.K.U., Pothupitiya S.N., Weerarathna R.S. and Dunuwila V.R. Factors affecting the level of stress among undergraduates in Sri Lanka with special reference to covid-19. Digital Library: University of Moratuwa, (2021)

6. Bolliger D.U. and Halupa C. Student perceptions of satisfaction and anxiety in an online doctoral program. Distance Education 33(1), (2012)

7. Cornine A. Reducing nursing student anxiety in the clinical setting: An integrative review. Nursing education perspectives. 41(4), 229-234 (2020)

8. Jones P.J., Park S.Y. and Lefevor G.T. Contemporary college student anxiety: The role of academic distress, financial stress, and support. Journal of College Counseling. 21(3), 252-264 (2018)

9. Ma H. and Miller C. Trapped in a double bind: Chinese overseas student anxiety during the COVID-19 pandemic. Health communication. 36(13), 1598-1605 (2021)

10. Cooper K.M., Downing V.R. and Brownell S.E. The influence of active learning practices on student anxiety in large-enrollment college science classrooms. International Journal of STEM Education. 5(1), 1-18 (2018)

11. Kosic A., Lindholm P., Järvholm K., Hedman-Lagerlöf E. and Axelsson E. Three decades of increase in health anxiety: Systematic review and meta-analysis of birth cohort changes in university student samples from 1985 to 2017. Journal of Anxiety Disorders. 71, p.102208 (2020)

12. Woldeab D. and Brothen T. 21st Century assessment: Online proctoring, test anxiety, and student performance. International Journal of E-learning and distance education. 34(1), (2019)

13. Rempel B.P., Dirks M.B. and McGinitie E.G. Two-stage testing reduces student-perceived exam anxiety in introductory chemistry. Journal of Chemical Education. 98(8), 2527-2535 (2021)

14. Bamber M.D. and Morpeth E. Effects of mindfulness meditation on college student anxiety: A meta-analysis. Mindfulness. 10(2), 203-214 (2019)

15. Anderson D. and Brown S. The effect of animal-assisted therapy on nursing student anxiety: A randomized control study. Nurse Education in Practice. 52, 103042 (2021)

16. Griffin M., Campos H.C., Khramtsova I. and Pearce A. Stress and Anxiety Reduction in College Students through Biofeedback. College Student Journal. 54(2), 258-268 (2020) 
17. Ibrahim A.K., Kelly S.J., Adams C.E. and Glazebrook C. A systematic review of studies of depression prevalence in university students. Journal of psychiatric research. 47(3), 391-400 (2013)

18. Puthran R., Zhang M.W., Tam W.W. and Ho R.C. Prevalence of depression amongst medical students: A meta-analysis. Medical education. 50(4), (2016)

19. Rotenstein L.S., Ramos M.A., Torre M., Segal J.B., Peluso M.J., Guille C., Sen S. and Mata D.A. Prevalence of depression, depressive symptoms, and suicidal ideation among medical students: a systematic review and meta-analysis. Jama. 316(21), 2214-2236 (2016)

20. Beiter R., Nash R., McCrady M., Rhoades D., Linscomb M., Clarahan M. and Sammut S. The prevalence and correlates of depression, anxiety, and stress in a sample of college students. Journal of affective disorders. 173, 90-96 (2015)

21. Rith-Najarian L.R., Boustani M.M. and Chorpita B.F. A systematic review of prevention programs targeting depression, anxiety, and stress in university students. Journal of Affective Disorders. 257, 568-584 (2019)

22. Satinsky E.N., Kimura T., Kiang M.V., Abebe R., Cunningham S., Lee H., Lin X., Liu C.H., Rudan I., Sen S. and Tomlinson M. Systematic review and meta-analysis of depression, anxiety, and suicidal ideation among Ph. D. students. Scientific Reports. 11(1), 1-12 (2021)

23. Lattie E.G., Adkins E.C., Winquist N., Stiles-Shields C., Wafford Q.E. and Graham A.K. Digital mental health interventions for depression, anxiety, and enhancement of psychological well-being among college students: systematic review. Journal of medical Internet research. 21(7), e12869 (2019)

24. Gao W., Ping S. and Liu X. Gender differences in depression, anxiety, and stress among college students: a longitudinal study from China. Journal of affective disorders. 263, 292-300 (2020)

25. Alsubaie M.M., Stain H.J., Webster L.A.D. and Wadman R. The role of sources of social support on depression and quality of life for university students. International Journal of Adolescence and Youth. 24(4), 484-496 (2019)

26. Wang Z.H., Yang H.L., Yang Y.Q., Liu D., Li Z.H., Zhang X.R., Zhang Y.J., Shen D., Chen P.L., Song W.Q. and Wang X.M. Prevalence of anxiety and depression symptom, and the demands for psychological knowledge and interventions in college students during COVID-19 epidemic: A large cross-sectional study. Journal of affective disorders. 275, 188-193 (2020)

27. Amarasuriya S.D., Jorm A.F. and Reavley N.J. Prevalence of depression and its correlates among undergraduates in Sri Lanka. Asian journal of psychiatry. 15, 32-37 (2015)

28. Amarasuriya S.D., Reavley N.J., Rossetto A. and Jorm A.F. Helping intentions of undergraduates towards their depressed peers: a cross-sectional study in Sri Lanka. BMC psychiatry. 17(1), (2017)

29. Pedersen D.E. Bipolar disorder and the college student: A review and implications for universities. Journal of American college health. 68(4), 341-346 (2020)

30. Vargas-Huicochea I., Robles-García R., Berlanga C., Tovilla-Zarate C.A., Martínez-López N. and Fresán A. Mental health literacy about bipolar disorder and schizophrenia among medical students: a comparative study of illness recognition, treatment, and attitudes according to perception of aggressiveness-dangerousness. Salud mental. 40(4), 141-148 (2017)

31. Shenoy S.K. and Praharaj S.K. Borderline personality disorder and its association with bipolar spectrum and binge eating disorder in college students from South India. Asian journal of psychiatry. 44, 20-24 (2019)

32. Li A., Teng J., Tajchman Z.J. and Vilares I. The Relationship between Bipolar and Borderline Personality Disorder traits, Impulsivity, and GPA among a college student population. PsyArXiv preprints, (2021)

33. Kate M.A., Hopwood, T. and Jamieson G. The prevalence of dissociative disorders and dissociative experiences in college populations: A meta-analysis of 98 studies. Journal of Trauma \& Dissociation. 21(1), 16-61 (2020)

34. Fung H.W., Ling H.H., Ross C.A., Tse J.L. and Liu R.K.W. Dissociative, Schneiderian and borderline personality symptoms in a non-clinical sample in Hong Kong: A preliminary report. European Journal of Trauma \& Dissociation. 4(1), 100076 (2020)

35. De Pasquale C., Dinaro C. and Sciacca F. Relationship of Internet gaming disorder with dissociative experience in Italian university students. Annals of general psychiatry. 17(1), 1-7 (2018)

36. Şar V., Türk T. and Öztürk E. Fear of happiness among college students: The role of gender, childhood psychological trauma, and dissociation. Indian journal of psychiatry. 61(4), 389 (2019)

37. Sonneville K.R. and Lipson S.K. Disparities in eating disorder diagnosis and treatment according to weight status, race/ethnicity, socioeconomic background, and sex among college students. International Journal of Eating Disorders. 51(6), 518-526 (2018)

38. Lipson S.K. and Sonneville K.R. Eating disorder symptoms among undergraduate and graduate students at 12 US colleges and universities. Eating behaviors. 24, 81-88 (2017)

39. Zickgraf H.F., Hazzard V.M., O'Connor S.M., Simone M., Williams-Kerver G.A., Anderson L.M. and Lipson S.K. Examining vegetarianism, weight motivations, and eating disorder psychopathology among college students. International Journal of Eating Disorders. 53(9), 1506-1514 (2020)

40. Ganson K.T. and Nagata J.M. Associations between vaping and eating disorder diagnosis and risk among college students Eating behaviors. 43, 101566 (2021)

41. Chan Y.L., Samy A.L., Tong W.T., Islam M.A. and Low W.Y., . Eating disorder among Malaysian University students and its associated factors. Asia Pacific Journal of Public Health. 32(6-7), 334-339 (2020) 
42. Blair L., Aloia C.R., Valliant M.W., Knight K.B., Garner J.C. and Nahar V.K. Association between athletic participation and the risk of eating disorder and body dissatisfaction in college students. International journal of health sciences. 11(4), p.8 (2017)

43. Cheng P.H. and Merrick E. Cultural adaptation of dialectical behavior therapy for a Chinese international student with eating disorder and depression. Clinical Case Studies. 16(1), $42-57$ (2017)

44. Stoeber J., Madigan D.J., Damian L.E., Esposito R.M. and Lombardo C. Perfectionism and eating disorder symptoms in female university students: The central role of perfectionistic self-presentation. Eating and Weight Disorders-Studies on Anorexia, Bulimia and Obesity. 22(4), 641-648 (2017)

45. Solly J.E., Chamberlain S.R., Lust K. and Grant J.E. Binge-eating disorder in university students: high prevalence and strong link to impulsive and compulsive traits. CNS spectrums, 1-9 (2021)

46. Stice E., Rohde P., Shaw H. and Gau J.M. Clinician-led, peer-led, and internet-delivered dissonance-based eating disorder prevention programs: Acute effectiveness of these delivery modalities. Journal of consulting and clinical psychology. 85(9), 883 (2017)

47. Jaisoorya T.S., Reddy Y.J., Nair B.S., Rani A., Menon P.G., Revamma M., Jeevan C.R., Radhakrishnan K.S., Jose V. and Thennarasu K., Prevalence and correlates of obsessive-compulsive disorder and subthreshold obsessive-compulsive disorder among college students in Kerala, India. Indian journal of psychiatry. 59(1), p.56 (2017)

48. Brytek-Matera A., Fonte M.L., Poggiogalle E., Donini L.M. and Cena H. Orthorexia nervosa: relationship with obsessivecompulsive symptoms, disordered eating patterns and body uneasiness among Italian university students. Eating and Weight Disorders-Studies on Anorexia, Bulimia and Obesity. 22(4), 609-617 (2017)

49. Shan H.D., Zhang R.T., Jiang S.Y., Wang Y.M., Liu Y.F., Cheung E.F. and Chan R.C. Schizotypal and obsessive-compulsive traits: Co-occurrence rate and relationship with executive function, emotion experience, and emotion expressivity in college students. Psych Journal. 9(5), 749-759 (2020)

50. Ji G., Wei W., Yue K.C., Li H., Shi L.J., Ma J.D., He C.Y., Zhou S.S., Zhao Z., Lou T. and Cheng J. Effects of the COVID-19 pandemic on obsessive-compulsive symptoms among university students: prospective cohort survey study. Journal of Medical Internet Research. 22(9), e21915 (2020)

51. Liu W., Li J., Huang Y., Yu B., Qin R. and Cao X. The relationship between left-behind experience and obsessive-compulsive symptoms in college students in China: the mediation effect of self-esteem. Psychology, health \& medicine. 26(5), 644-655 (2021)

52. Wheaton M.G. and Gallina E.R. Using cognitive-behavioral therapy to treat obsessive-compulsive disorder with co-occurring depression. Journal of Cognitive Psychotherapy. 33(3), 228-241 (2019)

53. Woerner M., Selles R.R., De Nadai A.S., Salloum A. and Storch E.A. Hoarding in college students: Exploring relationships with the obsessive compulsive spectrum and ADHD. Journal of Obsessive-Compulsive and Related Disorders. 12, 95-101 (2017)

54. Fuse-Nagase Y., Miura J., Namura I., Sato T., Yasumi K., Marutani T. and Sugita Y. Decline in the severity or the incidence of schizophrenia in Japan: A survey of university students. Asian journal of psychiatry. 24, 120-123 (2016)

55. Oswalt S.B., Lederer A.M., Chestnut-Steich K., Day C., Halbritter A. and Ortiz D. Trends in college students' mental health diagnoses and utilization of services, 2009-2015. Journal of American college health. 68(1), 41-51 (2020)

56. Newman-Taylor K., Kemp A., Potter H. and Au-Yeung S.K. An online investigation of imagery to attenuate paranoia in college students. Journal of Child and Family Studies. 27(3), 853-859 (2018)

57. Kingston J., Lassman F., Matias C. and Ellett L. Mindfulness and paranoia: a cross-sectional, longitudinal and experimental analysis. Mindfulness. 10(10), 2038-2045 (2019)

58. Sun X., So S.H.W., Chiu C.D., Chan R.C.K. and Leung P.W.L. Paranoia and anxiety: A cluster analysis in a non-clinical sample and the relationship with worry processes. Schizophrenia research. 197, 144-149 (2018)

59. Harper D.J. and Timmons C. How is paranoia experienced in a student population? A qualitative study of students scoring highly on a paranoia measure. Psychology and Psychotherapy: Theory, Research and Practice. 94(1), 101-118 (2021)

60. Li Y., Cao F., Cao D. and Liu J. Nursing students' post-traumatic growth, emotional intelligence and psychological resilience. Journal of psychiatric and mental health nursing. 22(5), pp.326-332 (2015)

61. Arpawong T.E., Sussman S., Milam J.E., Unger J.B., Land H., Sun P. and Rohrbach L.A. Post-traumatic growth, stressful life events, and relationships with substance use behaviors among alternative high school students: A prospective study. Psychology \& health. 30(4), 475-494 (2015)

62. Perfect M.M., Turley M.R., Carlson J.S., Yohanna J. and Saint Gilles M.P. School-related outcomes of traumatic event exposure and traumatic stress symptoms in students: A systematic review of research from 1990 to 2015. School Mental Health. 8(1), 7-43 (2016)

63. Richardson T., Yeebo M., Jansen M., Elliott P. and Roberts R. Financial difficulties and psychosis risk in British undergraduate students: a longitudinal analysis. Journal of Public Mental Health, (2018)

64. Andorko N.D., Mittal V., Thompson E., Denenny D., Epstein G., Demro C., Wilson C., Sun S., Klingaman E.A., DeVylder J. and $\mathrm{Oh} \mathrm{H}$. The association between sleep dysfunction and psychosis-like experiences among college students. Psychiatry Research. 248, 6-12 (2017)

65. Sanderson V.A., Vandyk A.D., Graham I.D., Lightfoot S., Murawsky M., Sikora L. and Jacob J.D. Post-secondary students with symptoms of psychosis: A mixed-methods systematic review. International journal of mental health nursing. 29(4), 590-607 (2020) 
66. Luo X., Zhang L., Zhang J., Chen H., Hong H., Luo R., Ma L., Wang C., Jin F., Wang E. and Jiang Z. Changes in the cognitive function of Chinese college students with a clinical high risk of psychosis. Psychiatry research. 305, 114242 (2021)

67. Thompson E.C., Andorko N.D., Rakhshan Rouhakhtar P., Millman Z.B., Sagun K., Han S., Chibani D., Reeves G.M., Herman B. and Schiffman J. Psychosis-Spectrum Screening and Assessment within a College Counseling Center: A Pilot Study Exploring Feasibility and Clinical Need. Journal of College Student Psychotherapy, 1-22 (2020)

68. Shi J., Wang L., Yao Y., Chen F., Su N., Zhao X. and Zhan C. Protective factors in Chinese university students at clinical high risk for psychosis. Psychiatry Research. 239, 239-244 (2016)

69. Kessler R.C., Barker P.R., Colpe L.J., Epstein J.F., Gfroerer J.C., Hiripi E., Howes M.J., Normand S.L.T., Manderscheid R.W., Walters E.E. and Zaslavsky A.M. Screening for serious mental illness in the general population. Archives of general psychiatry. 60(2), 184-189 (2003)

70. Lamers S.M., Westerhof G.J., Bohlmeijer E.T., ten Klooster P.M. and Keyes C.L. Evaluating the psychometric properties of the mental health continuum-short form (MHC-SF). Journal of clinical psychology. 67(1), pp.99-110 (2011)

71. Angle S.P. Perceptions of college students diagnosed with panic disorder with agoraphobia: Academic, psychosocial, and environmental views of their college experience. Virginia Polytechnic Institute and State University. Ph.D thesis, (1999)

72. Jurin T. and Biglbauer S. Anxiety sensitivity as a predictor of panic disorder symptoms: a prospective 3-year study. Anxiety, Stress, \& Coping. 31(4), 365-374 (2018)

73. Desalegn G.T., Getinet W. and Tadie G. The prevalence and correlates of social phobia among undergraduate health science students in Gondar, Gondar Ethiopia. BMC research notes, 12(1), 1-6 (2019)

74. RABIE M.A., Shorab E., ElGabry D., Aziz K.A., Sabry W.M., Aufa O., ElGhamry R., Hassan G. and Nagy N. Screening of social phobia symptoms in a sample of Egyptian university students. Archives of Clinical Psychiatry (São Paulo). 46, 27-32 (2019)

75. Elavarasan K., Dhandapani T., Norman P., Vidya D.C. and Mani G. The association between internet addiction, social phobia and depression in medical college students. International Journal of Community Medicine and Public Health. 5(10), 4351-4356 (2018)

76. Akram M.S., Naik P. and Nirgude A.S. A study on social phobia and functional disability among university students of dakshina kannada district. Hindu. 112, 34-4 (2015)

77. Baker A., Simon N., Keshaviah A., Farabaugh A., Deckersbach T., Worthington J.J., Hoge E., Fava M. and Pollack M.P. Anxiety Symptoms Questionnaire (ASQ): development and validation. General psychiatry. 32(6), (2019)

78. Lasa L., Ayuso-Mateos J.L., Vázquez-Barquero J.L., Diez-Manrique F.J. and Dowrick C.F. The use of the Beck Depression Inventory to screen for depression in the general population: a preliminary analysis. Journal of affective disorders. 57(1-3), 261-265 (2000)

79. Hirschfeld R.M., Williams J.B., Spitzer R.L., Calabrese J.R., Flynn L., Keck Jr P.E., Lewis L., McElroy S.L., Post R.M., Rapport D.J. and Russell J.M. Development and validation of a screening instrument for bipolar spectrum disorder: the Mood Disorder Questionnaire. American journal of psychiatry. 157(11), 1873-1875 (2000)

80. Nijenhuis E.R., Spinhoven P., Van Dyck R., Van der Hart O. and Vanderlinden J. The development of the somatoform dissociation questionnaire (SDQ-5) as a screening instrument for dissociative disorders. Acta Psychiatrica Scandinavica. 96(5), 311-318 (1997)

81. Gideon N., Hawkes N., Mond J., Saunders R., Tchanturia K. and Serpell L. Development and psychometric validation of the EDE-QS, a 12 item short form of the Eating Disorder Examination Questionnaire (EDE-Q). PLoS One. 11(5), e0152744 (2016)

82. Mallet J., Lancrenon S., Llorca P.M., Lançon C., Baylé F.J. and Gorwood P. Validation of a four items version of the Functional Remission of General Schizophrenia scale (the mini-FROGS) to capture the functional benefits of clinical remission. European Psychiatry. 47, 35-41 (2018)

83. Freeman D., Bird J.C., Loe B.S., Kingdon D., Startup H., Clark D.M., Ehlers A., Černis E., Wingham G., Evans N. and Lister R. The Dunn worry questionnaire and the paranoia worries questionnaire: new assessments of worry. Psychological medicine. 50(5), $771-780(2020)$

84. Loewy R.L., Bearden C.E., Johnson J.K., Raine A. and Cannon T.D. The prodromal questionnaire (PQ): preliminary validation of a self-report screening measure for prodromal and psychotic syndromes. Schizophrenia research. 79(1), 117-125 (2005) 